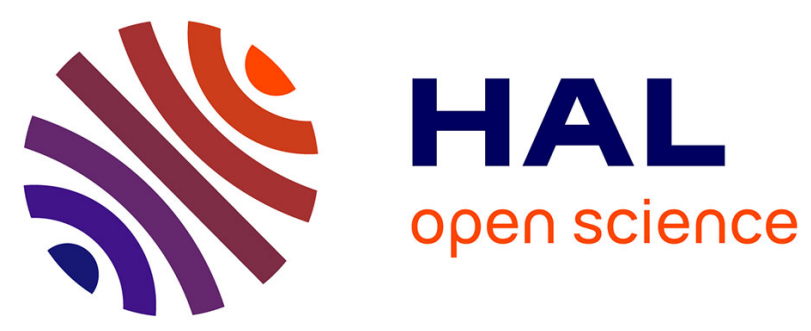

\title{
Inhibition of iron-induced lipid peroxidation by newly identified bacterial carotenoids in model gastric conditions: comparison with common carotenoids.
} Charlotte Sy, Catherine Caris-Veyrat, Claire Dufour, Malika Boutaleb, Patrick Borel, Olivier Dangles

\section{To cite this version:}

Charlotte Sy, Catherine Caris-Veyrat, Claire Dufour, Malika Boutaleb, Patrick Borel, et al.. Inhibition of iron-induced lipid peroxidation by newly identified bacterial carotenoids in model gastric conditions: comparison with common carotenoids.. Food and Function, 2013, 4 (5), pp.698-712. 10.1039/c3fo30334a . hal-01328665

\section{HAL Id: hal-01328665 https://hal.science/hal-01328665}

Submitted on 28 May 2020

HAL is a multi-disciplinary open access archive for the deposit and dissemination of scientific research documents, whether they are published or not. The documents may come from teaching and research institutions in France or abroad, or from public or private research centers.
L'archive ouverte pluridisciplinaire HAL, est destinée au dépôt et à la diffusion de documents scientifiques de niveau recherche, publiés ou non, émanant des établissements d'enseignement et de recherche français ou étrangers, des laboratoires publics ou privés. 
Cite this: DOI: $10.1039 /$ c3fo30334a

Received 22nd November 2012

Accepted 26th January 2013

DOI: $10.1039 / \mathrm{c} 3 \mathrm{fo} 30334 \mathrm{a}$

www.rsc.org/foodfunction

\title{
Inhibition of iron-induced lipid peroxidation by newly identified bacterial carotenoids in model gastric conditions: comparison with common carotenoids
}

\author{
Charlotte Sy, ${ }_{1}^{\text {ae }}$ Catherine Caris-Veyrat, ${ }^{\text {ab }}$ Claire Dufour, $^{\text {ab }}$ Malika Boutaleb, ${ }^{\text {ab }}$ \\ Patrick Borel ${ }^{\text {cde }}$ and Olivier Dangles ${ }^{* a b}$
}

\begin{abstract}
Newly identified spore-forming pigmented marine bacteria, Bacillus indicus HU36 and Bacillus firmus GB1, are sources of carotenoids (mainly 15 yellow and orange pigments and 13 pink pigments, respectively) with original structures. These bacterial carotenoids were evaluated for their ability to inhibit the iron-induced peroxidation of linoleic acid micelles, or sunflower oil-in-water emulsions, in comparison with $\beta$-carotene, lycopene and astaxanthin. Lipid peroxidation was carried out in acidic conditions and initiated by dietary heme or non-heme iron (metmyoglobin or Fe", respectively) so as to simply simulate the postprandial gastric medium, a possible site for dietary oxidative stress. Lipid hydroperoxide formation and carotenoid consumption were followed by UV-vis spectroscopy and appropriate indicators of the antioxidant activity were estimated in each model. The bacterial carotenoids were found to be better inhibitors of heme-induced lipid peroxidation than the reference carotenoids as a likely consequence of their location closer to the interface in micelles and lipid droplets. However, this trend was not confirmed in lipid peroxidation induced by non-heme iron, possibly because of the redox recycling of $\mathrm{Fe}^{\prime \prime}$ by carotenoids. The quantitative kinetic analysis of the peroxidation curves suggests that the carotenoids mainly inhibit the propagation phase of lipid peroxidation by direct scavenging of the lipid peroxyl radicals, in agreement with independent experiments showing that carotenoids are unable to reduce the one-electron oxidized form of metmyoglobin (ferrylmyoglobin), a model of initiating species in heme-induced lipid peroxidation. Overall, carotenoids from Bacillus indicus HU36 and Bacillus firmus GB1 were found to be interesting antioxidants to fight postprandial oxidative stress in the stomach.
\end{abstract}

\section{Introduction}

Lipid oxidation is detrimental to food quality and to the integrity of biological lipid assemblies (cell membranes, lipoproteins). ${ }^{1,2}$ When initiated by reactive oxygen species (ROS) under oxidative stress conditions, lipid peroxidation is a radical chain mechanism producing lipid hydroperoxides (primary products) and a complex distribution of secondary products via reactive lipid oxyl and peroxyl radicals. ${ }^{3}$ Radicals and electrophiles (aldehydes, epoxides) formed during lipid peroxidation can also damage proteins and DNA and those events are involved in the development of degenerative diseases. ${ }^{4-7}$

aINRA, UMR408, Sécurité et Qualité des Produits d'Origine Végétale, F-84000 Avignon, France. E-mail: Olivier.Dangles@univ-avignon.fr; Fax: +33 4901444 41; Tel: +33 490 144446

${ }^{b}$ University of Avignon, UMR408, Sécurité et Qualité des Produits d'Origine Végétale, F-84000 Avignon, France

'INRA, UMR1260, Nutrition Obesity and Risk of Thrombosis, F-13385, Marseille, France

${ }^{d}$ INSERM, UMR 1062, F-13385, Marseille, France

${ }^{e}$ Aix-Marseille University, Faculté de Médecine, F-13385 Marseille, France
Dietary iron, which is abundant in meat in its heme and free forms,${ }^{8}$ is a major initiator of lipid oxidation in food due to its ability to produce ROS from hydroperoxide traces. ${ }^{9,10}$ Similar reactions may occur in the digestive tract after ingestion of dietary iron and polyunsaturated fatty acids (PUFAs). In gastric conditions, dietary lipid peroxidation may be especially fast due to high dioxygen concentrations, acidic $\mathrm{pH}$ and constant mixing. ${ }^{11,12}$

Because of their limited intestinal absorption and extensive catabolism in humans, polyphenols and carotenoids, the main dietary antioxidants together with vitamins $\mathrm{C}$ and $\mathrm{E}$, are being increasingly considered to exert a large part of their beneficial health effects in the gastro-intestinal (GI) tract, ${ }^{13,14}$ in particular by inhibiting the peroxidation of dietary PUFAs. It is therefore biologically significant to devise simple chemical models of the gastric content for investigating the capacity of dietary antioxidants to scavenge ROS formed during iron-induced lipid peroxidation..$^{15-19}$

Pigmented microorganisms are interesting sources of original pigments with potential nutritional value such as carotenoids. As such, they could find application in the food industry, e.g. as colorants and dietary supplements. In this work, newly 


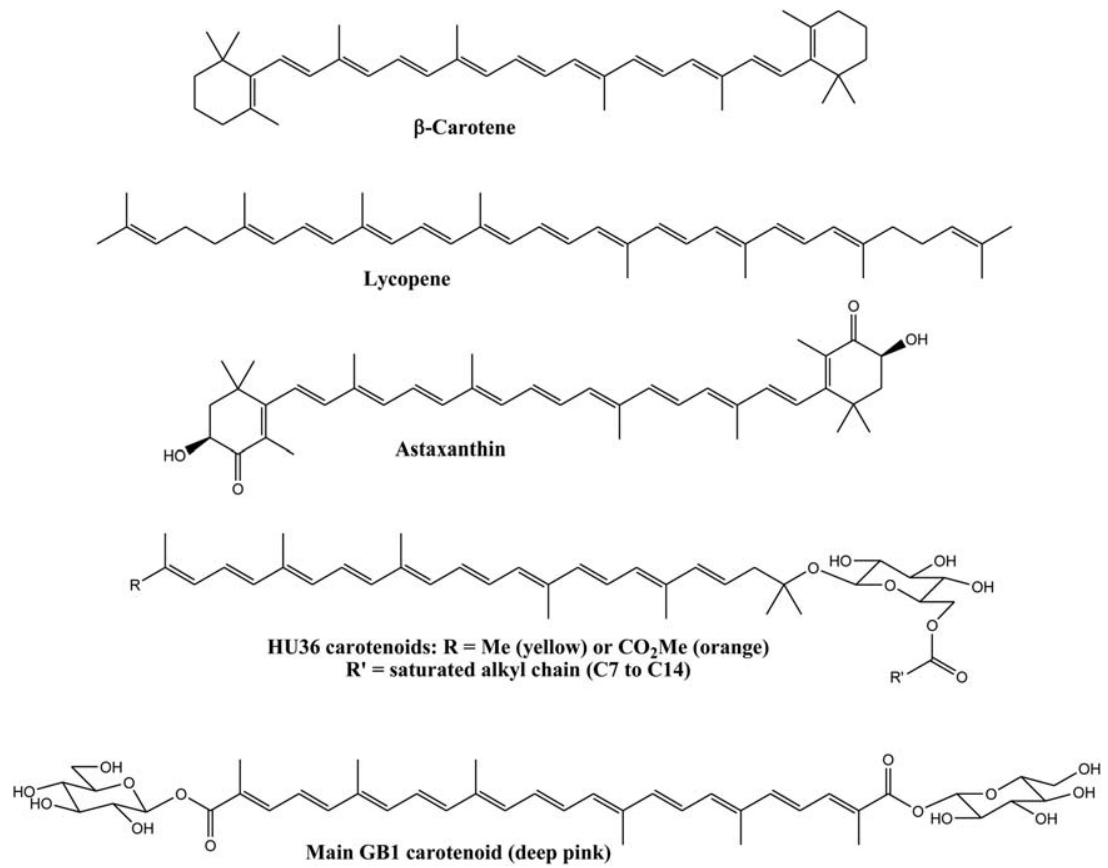

Scheme 1 Structures of the carotenoids investigated. In HU36 and GB1, the configurations of the sugar C-atoms as well as the site of acylation are tentatively attributed.

identified carotenoids extracted from two marine bacterial strains (Scheme 1) were investigated for their antioxidant activity in gastric content. Initially, the Bacillus indicus HU36 and the mutant Bacillus firmus GB1 strains were selected for their high production of carotenoids, the resistance of their spores to UV radiation and their probiotic properties. ${ }^{20,21}$ The HU36 strain isolated from human faeces produces yellow and orange pigments $\left(\lambda_{\max }=429,454\right.$ and $\left.485 \mathrm{~nm}\right)$ in variable proportions depending on whether they are in the forms of vegetative cells or spores. The most abundant pigments in HU36 are glycosides of oxygenated lycopene derivatives (apolycopenoids) acylated by saturated fatty acid chains on the sugar moiety. ${ }^{22}$ The GB1 strain isolated from human ileum produces deep-pink pigments $\left(\lambda_{\max }=463,492\right.$ and $524 \mathrm{~nm}$ ), the main one being $4,4^{\prime}$-diglycosyl-4,4'-diapolycopenoic ester. ${ }^{20}$ For comparison, three common carotenoids were also investigated: the hydrocarbons $\beta$-carotene and lycopene abundant in fruit and vegetables, and the xanthophyll astaxanthin produced by yeasts and typically consumed with fishes and crustaceans. These three pigments are among the most common commercially available carotenoids either in synthetic or natural form..$^{23}$

Our models of lipid peroxidation in the stomach involve mildly acidic micelle solutions of linoleic acid and sunflower oil-in-water emulsions. The experimental conditions used were adapted from previously published procedures. ${ }^{15-19}$ Peroxidation was initiated either by free ferrous iron or by metmyoglobin and followed at pH 5.8 and 4, respectively corresponding to the early phase and the mid-phase of gastric digestion. ${ }^{24}$ Insights into the antioxidant mechanisms involved were achieved through a combination of approaches: (a) a detailed physico-chemical modelling of iron-induced lipid peroxidation in the presence or absence of an antioxidant, (b) the assessment of the carotenoid partition between the oil and aqueous phases of the emulsion, and (c) the ability of carotenoids to reduce ferrylmyoglobin, a one-electron oxidized form of metmyoglobin and a model of initiating species in heme-induced lipid peroxidation.

\section{Experimental section}

\subsection{Chemicals}

(all- $E$ )-Lycopene from tomato oleoresin $\left(\mathrm{C}_{40} \mathrm{H}_{56}, M=536 \mathrm{~g} \mathrm{~mol}^{-1}\right.$, $>90 \%$ ) was from Conesa (Badajoz, Spain). Newly identified carotenoid extracts from Bacillus strains (HU36 and GB1) were provided by members of the Colorspore consortium (Small Collaborative Project no. 207948, FP7). (all- $E$ )- $\beta$-Carotene $\left(\mathrm{C}_{40} \mathrm{H}_{56}\right.$, $\left.M=536 \mathrm{~g} \mathrm{~mol}^{-1},>95 \%\right)$, (all- $E$ )-astaxanthin $\left(\mathrm{C}_{40} \mathrm{H}_{52} \mathrm{O}_{4}, M=596 \mathrm{~g}\right.$ $\mathrm{mol}^{-1},>98 \%$ ), polyoxyethyleneglycol 23 lauryl ether (Brij®35), (9Z,12Z)-octadecadienoic acid (linoleic acid, >99\%), $\mathrm{L}-\alpha$-lecithin from soybean ( $>50 \% \quad \alpha$-phosphatidylcholine), $\quad \mathrm{FeSO}_{4} \cdot 7 \mathrm{H}_{2} \mathrm{O}$ (>99.5\%), myoglobin from equine heart (>90\%, salt-free), xylenol orange tetrasodium salt and BHT (2,6-di-t-butyl-p-cresol) were purchased from Sigma-Aldrich (St-Quentin-Fallavier, France). Ferrozine (3-(2-pyridyl)-5,6-diphenyl-1,2,4-triazine-4'-4" $\%$-disulfonic acid monosodium, 97\%) was from Fluka (St-Quentin-Fallavier, France). Sunflower oil was food grade (Auchan store, France). Water was purified through a Millipore Q-Plus.

A stock $1 \mathrm{mM} \mathrm{Fe}{ }^{\mathrm{II}}$ solution was prepared in $0.1 \mathrm{M}$ aqueous $\mathrm{H}_{2} \mathrm{SO}_{4}$. Stock metmyoglobin $\left(\mathrm{MbFe}^{\mathrm{III}}\right)$ solutions were prepared in Milli-Q water, filtered through a $0.45 \mu \mathrm{m}$ filter and their concentrations checked by absorbance measurement at $525 \mathrm{~nm}$ using $\varepsilon=7700 \mathrm{M}^{-1} \mathrm{~cm}^{-1} .{ }^{25}$ Metmyoglobin concentrations were adjusted to $25 \mu \mathrm{M}$ and $1 \mathrm{mM}$ for experiments in the micelle and emulsion models, respectively. 


\subsection{Purification and analysis of bacterial carotenoids}

Crude bacterial extracts from HU36 and GB1 were purified by liquid chromatography on a $\mathrm{C} 18$ silica column (elution by a gradient of $\mathrm{MeOH}-\mathrm{H}_{2} \mathrm{O}(4: 1)$ and EtOAc- $\left.\mathrm{CH}_{2} \mathrm{Cl}_{2}(4: 1)\right)$. The average molecular weights of the HU36 and GB1 carotenoids (750 $\mathrm{g} \mathrm{mol}^{-1}$ and $784 \mathrm{~g} \mathrm{~mol}^{-1}$ respectively) were estimated by UPLC (Waters Acquity) coupled to a diode-array detector and QTOF mass spectrometer (HCTTM high capacity trap Ultra MSR, Bruker Daltonics). Samples were eluted at $35^{\circ} \mathrm{C}$ on a C18 silica column $(2.1 \times 150 \mathrm{~mm}, 1.8 \mu \mathrm{m}$ particle size, type HSS T3, Waters Acquity) with a gradient of solvent $\mathrm{A}\left(5 \mu \mathrm{M} \mathrm{HCO}_{2} \mathrm{H}+10 \mathrm{mM}\right.$ $\mathrm{HCO}_{2} \mathrm{NH}_{4}$ in $\left.\mathrm{MeCN}-\mathrm{MeOH}-\mathrm{H}_{2} \mathrm{O}(4: 1: 1)\right)$ and solvent $\mathrm{B}(5 \mu \mathrm{M}$ $\mathrm{HCO}_{2} \mathrm{H}$ in EtOAc- $\left.\mathrm{CH}_{2} \mathrm{Cl}_{2}(4: 1)\right)$ at a flow rate of $0.5 \mathrm{~mL} \mathrm{~min}^{-1}$. Mean molecular masses were calculated from the molecular masses of individual carotenoids weighed by the area of peaks.

Stock standard carotenoid solutions ( $c a .0 .5 \mathrm{mM}$ ) were prepared in $10 \mathrm{~mL} \mathrm{CH}_{2} \mathrm{Cl}_{2}$. The concentrations of stock carotenoid solutions were calculated by UV-visible spectroscopy. The molar absorption coefficients used were $128.5 \times 10^{3} \mathrm{M}^{-1} \mathrm{~cm}^{-1}$ at $460 \mathrm{~nm}$ for $\beta$-carotene, $178 \times 10^{3} \mathrm{M}^{-1} \mathrm{~cm}^{-1}$ at $482 \mathrm{~nm}$ for lycopene and $125 \times 10^{3} \mathrm{M}^{-1} \mathrm{~cm}^{-1}$ at $486 \mathrm{~nm}$ for astaxanthin. ${ }^{26}$ The molar absorption coefficients at $\lambda_{\max }$ of the bacterial carotenoids in petroleum ether were taken equal to the ones of closely related analogues found in Staphylococcus aureus, ${ }^{27}$ i.e. staphyloxanthin for HU36, glucosyl-diaponeurosporenoate for GB1. They were then calculated in $\mathrm{CH}_{2} \mathrm{Cl}_{2}$ from the UV-visible spectra recorded in both solvents: $\varepsilon=165 \times 10^{3} \mathrm{M}^{-1} \mathrm{~cm}^{-1}$ at $454 \mathrm{~nm}$ for HU36 carotenoids and $225.3 \times 10^{3} \mathrm{M}^{-1} \mathrm{~cm}^{-1}$ at $502 \mathrm{~nm}$ for GB1 carotenoids.

All spectra were recorded on a Specord S-600 diode-array UVVis spectrophotometer (optical pathlength $=1 \mathrm{~cm}$ ) equipped with an 8-cell rail, a magnetic stirring device and a thermostatic bath (Analytik Jena).

\subsection{Lipid peroxidation in the micelle model}

A $0.2 \mathrm{M}$ acetate buffer and a $0.2 \mathrm{M}$ phosphate buffer were chosen for experiments at $\mathrm{pH} 4.0$ and 5.8, respectively. Under these conditions, the metal-chelating capacity of the phosphate buffer was too low to remove iron from heme. Because of potential contamination by metal traces, purification of buffer solutions was achieved by elution on a chelating resin (Chelex $100 \AA$, Bio-Rad). The non-ionic surfactant Brij®35 (polyoxyethyleneglycol dodecyl ether) was used for the preparation of carotenoid-containing micelles. Brij ${ }^{\circledR} 35$ was chosen for its good stability and very low content of hydroperoxides, which could react with iron. ${ }^{28}$ Aliquots of stock carotenoid solutions were mixed with $2 \mathrm{~mL}$ of a $40 \mathrm{mM}$ stock solution of Brij®35 in $\mathrm{CH}_{2} \mathrm{Cl}_{2}$ and $250 \mu \mathrm{L}$ of a $28 \mathrm{mM}$ stock solution of linoleic acid in $\mathrm{CH}_{2} \mathrm{Cl}_{2}$. After evaporation of $\mathrm{CH}_{2} \mathrm{Cl}_{2}$ under reduced pressure and solubilisation of the dried viscous residue in $20 \mathrm{~mL}$ aqueous buffer, initial concentrations were $4 \mathrm{mM}$ Brij ${ }^{\circledR} 35,0.7 \mathrm{mM}$ linoleic acid and 0-8 $\mu \mathrm{M}$ carotenoid.

In the lipid peroxidation experiments, $1.96 \mathrm{~mL}$ of the micelle solution containing $\operatorname{Brij}{ }^{\circledR} 35$, linoleic acid with or without carotenoid were transferred into the spectrophotometer cells protected from light, covered with Teflon stoppers and under magnetic stirring at $37{ }^{\circ} \mathrm{C}$. Oxidation was initiated by addition of $40 \mu \mathrm{L}$ iron solution. At $\mathrm{pH} 4$, oxidation was initiated by $\mathrm{Fe}^{\mathrm{II}}$ (concentration in cell: $20 \mu \mathrm{M}$ ) or $\mathrm{MbFe}^{\mathrm{III}}$ (concentration in cell: $0.5 \mu \mathrm{M})$. At $\mathrm{pH} 5.8$, only $\mathrm{MbFe}^{\mathrm{III}}$ was used because of the poor solubility of $\mathrm{Fe}^{\mathrm{II}}$. Each experiment was run in triplicate. Lipid peroxidation was followed by monitoring the concentration of conjugated dienes at $234 \mathrm{~nm}$. The residual carotenoid concentration was simultaneously measured at the $\lambda_{\max }$ value in the visible range.

\subsection{Lipid peroxidation in the emulsion model}

The experimental procedure was adapted from our previous works. ${ }^{18,19}$ Experiments were carried out at pH 4 (20 mM acetate buffer) and $37^{\circ} \mathrm{C}$. Sunflower oil was stripped from endogenous $\alpha$ tocopherol by adsorption on activated neutral alumina ( $15 \mathrm{~g}$ per $30 \mathrm{~mL}$ oil) at $4{ }^{\circ} \mathrm{C}$ for $24 \mathrm{~h}$. Its fatty acid composition was around $63 \% 18: 2 n-6,25 \% 18: 1 n-9,7 \% 16: 0$ and 5\% $18: 0$. An aliquot of stock carotenoid solution (concentration calculated by absorbance measurement) and $638 \mathrm{mg}$ soya phospholipids (53\% in $\alpha$-phosphatidylcholine, $31 \%$ in phosphatidylethanolamine, $12 \%$ in sphingomyeline and $4 \%$ in phosphatidylinositol) were dispersed into $1.8 \mathrm{~g}$ sunflower oil. After evaporation of the solvent under reduced pressure, the dried viscous residue was mixed with $16.4 \mathrm{~mL}$ acetate buffer and homogenised by vigorous stirring to initiate emulsification. Then, the mixture was kept in ice and emulsification was completed by sonication for $6 \times 45 \mathrm{~s}$. The final carotenoid concentration in the emulsion was 25 or $100 \mu \mathrm{M}$.

Emulsions were first analysed by optical microscopy $\left(\times 10^{3}\right)$. Then, the particle size distributions of the emulsion droplets were measured using a laser diffraction instrument (Mastersizer 2000, Malvern Instruments). The particle size was determined at different time points of the reaction and with several emulsions.

For investigating the partition of carotenoids in emulsions, $5 \mathrm{~mL}$ of the oil-in-water emulsion at $\mathrm{pH} 4$ were transferred to polyvinyl flasks. Ultracentrifugation was conducted at $35 \times 10^{3}$ rpm for $1 \mathrm{~h}$ at $4{ }^{\circ} \mathrm{C}$. Two phases were collected: a lipid supernatant and an aqueous lower phase. Carotenoids were extracted in $\mathrm{CH}_{2} \mathrm{Cl}_{2}$ from the two phases and their concentrations were measured by UV-visible spectroscopy.

In the lipid peroxidation experiments, $5 \mathrm{~mL}$ of the oil-inwater emulsion at $\mathrm{pH} 4$ were transferred into small glass flasks protected from light and kept under magnetic stirring at $37^{\circ} \mathrm{C}$. Oxidation was initiated by addition of $c a .200 \mu \mathrm{L} \mathrm{MbFe}^{\mathrm{III}}$ solution to the reaction medium (final $\mathrm{MbFe}^{\mathrm{III}}$ concentration: $40 \mu \mathrm{M})$. Each experiment was monitored for $6 \mathrm{~h}$ and run in triplicate. Aliquots $(100 \mu \mathrm{L})$ were taken up, diluted in $1.9 \mathrm{~mL}$ $\mathrm{iPrOH}$, centrifuged at $10^{4} \mathrm{rpm}$ for $2 \mathrm{~min}$ and analyzed by UVvisible spectroscopy to determine the carotenoid concentration (absorbance measurement at $\lambda_{\max }$ ). Then, $200 \mu \mathrm{L}$ of the supernatant were collected and diluted again in $1.8 \mathrm{~mL}$ iPrOH. Lipid peroxidation was followed by measuring the concentration of conjugated dienes at $233 \mathrm{~nm}$.

\section{$2.5 \mathrm{Fe}^{\mathrm{II}}$ and $\mathrm{Fe}^{\mathrm{III}}$ titrations}

$\mathrm{Fe}^{\mathrm{II}}$-induced peroxidation experiments in the micelle model were repeated in round bottom flasks with larger volumes of 
solution to permit the monitoring of the redox state of iron. Aliquots $(1 \mathrm{~mL})$ of the medium were taken up at $t=0$ (before addition of iron), 2, 6, 12, 20, 30, 45, 60, 90 and $120 \mathrm{~min}$. The carotenoid and its products were extracted in $\mathrm{CH}_{2} \mathrm{Cl}_{2}$. After 2 min centrifugation at $10^{4} \mathrm{rpm}, 250 \mu \mathrm{L}$ of the aqueous phase were mixed with $750 \mu \mathrm{L}$ of a $1 \mathrm{mM}$ ferrozine solution in Milli-Q water for $\mathrm{Fe}^{\mathrm{II}}$ titration. ${ }^{29}$ Titration of $\mathrm{Fe}^{\mathrm{III}}$ was adapted from the FOX2 method typically used for $\mathrm{H}_{2} \mathrm{O}_{2}$ titration. ${ }^{30} \mathrm{~A} 10^{-4} \mathrm{M}$ solution of xylenol orange in $\mathrm{MeOH} / 0.25 \mathrm{M} \mathrm{H}_{2} \mathrm{SO}_{4}(9: 1)$ was used to that purpose. After $15 \mathrm{~min}$ incubation at room temperature, a stable coloration was obtained. The samples were then transferred to the spectrophotometer cell for recording the absorbance at 564 $\mathrm{nm}$ for $\mathrm{Fe}^{\mathrm{II}}$ and at $559 \mathrm{~nm}$ for $\mathrm{Fe}^{\mathrm{III}}$. Calibration curves, previously constructed using $\mathrm{Fe}^{\mathrm{II}}$ and $\mathrm{Fe}^{\mathrm{III}}$ solutions in acetate buffer, were linear in the range $0.5-150 \mu \mathrm{M}$ for $\mathrm{Fe}^{\mathrm{II}}$ and $0.5-125 \mu \mathrm{M}$ for $\mathrm{Fe}^{\mathrm{III}}$.

\subsection{Reduction of ferrylmyoglobin by the carotenoids}

The experimental procedure was adapted from the literature. ${ }^{15}$ Ferrylmyoglobin $\left(\mathrm{MbFe}^{\mathrm{IV}}=\mathrm{O}\right)$ was first formed in the spectrophotometer cell by adding $60 \mu \mathrm{L}$ of a concentrated aqueous solution of $\mathrm{H}_{2} \mathrm{O}_{2}$ (final concentration in the cell $=30 \mu \mathrm{M}$ ) to a $60 \mu \mathrm{M} \mathrm{MbFe}{ }^{\mathrm{III}}$ solution in a pH 7 phosphate buffer containing $4 \mathrm{mM}$ Brij ${ }^{\circledR} 35$. Spectral changes featuring the conversion of $\operatorname{MbFe}^{\mathrm{III}}\left(\lambda_{\max }=505 \mathrm{~nm}\right)$ into $\mathrm{MbFe}^{\mathrm{IV}}=\mathrm{O}\left(\lambda_{\max }=590 \mathrm{~nm}\right)$ were recorded in the visible range until stability (2-3 $\mathrm{min})$. Then, $50 \mu \mathrm{L}$ of a concentrated solution of carotenoid in $\mathrm{MeOH}-\mathrm{THF}$ $(1 / 1, v / v)$ were added (final carotenoid concentrations in the cell $=25$ or $100 \mu \mathrm{M}$ ) and the reduction of $\mathrm{MbFe}^{\mathrm{IV}}=\mathrm{O}$ back to $\mathrm{MbFe}^{\mathrm{III}}$ was monitored at $590 \mathrm{~nm}$.

\subsection{Kinetic analysis}

All calculations and simulations were carried out with the Scientist program (MicroMath, Salt Lake City, USA). Standard deviations are reported. Sets of differential kinetic equations (see Annexes) with initial conditions on concentrations were given as input data. Curve fittings were achieved through least- squares regression and yielded optimized values for the kinetic and stoichiometric parameters.

\subsection{Statistical analysis}

ANOVA tests were run on the StatView software (version 5.0, SAS Institute Inc., Cary, USA).

\section{Results}

\subsection{Inhibition of lipid peroxidation by carotenoids in the micelle model}

A typical spectroscopic monitoring of inhibited lipid peroxidation (Fig. 1) shows the consumption of carotenoids followed by the accumulation of conjugated dienes (CDs). Kinetic curves can then be plotted with increasing carotenoid concentrations (Fig. 2 and 3). In all three models, inhibited peroxidation was characterized by more or less pronounced induction phases (very slow CD accumulation) corresponding to the period necessary to consume the carotenoids. In $\mathrm{MbFe}^{\mathrm{III}}$-initiated oxidation (Fig. 2), the propagation rate with both reference and bacterial carotenoids (even after total consumption of carotenoids) was lower than in the control. In $\mathrm{Fe}^{\mathrm{II}}$-initiated oxidation (Fig. 3), the carotenoids had little effect on the propagation rate. In the longer run, saturation in $\mathrm{CD}$ accumulation was finally observed. Whatever the carotenoid, $\mathrm{MbFe}^{\mathrm{III}}$-induced lipid peroxidation was globally faster at $\mathrm{pH} 4$ than at $\mathrm{pH} 5.8$ (data not shown). Indeed, at $\mathrm{pH} 5.8$, the initiator is the intact metalloprotein, while at $\mathrm{pH} 4$ denaturation takes place and the peroxidation is initiated by the sole cofactor (hematin). ${ }^{\mathbf{1 6}}$

For a first quantitative estimation of the antioxidant capacity, the following time periods were estimated: $T_{0}=$ time period required to produce a fixed $\mathrm{CD}$ concentration in the control experiment, e.g. that corresponding to a 0.7 increase in the absorbance at $234 \mathrm{~nm}$ from its value at time zero (addition of iron), and $T=$ time period required to produce the same $\mathrm{CD}$ concentration in the presence of carotenoids. The $T / T_{0}$ ratio was

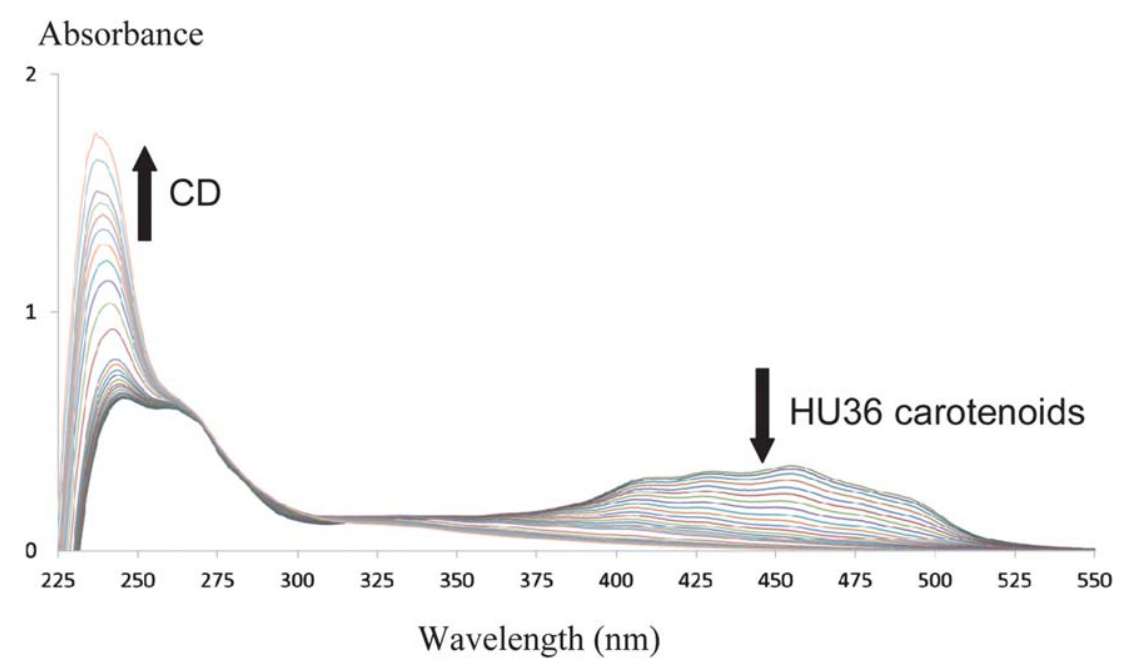

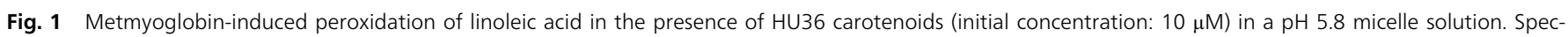
troscopic monitoring over $90 \mathrm{~min}$. CD: conjugated dienes. 

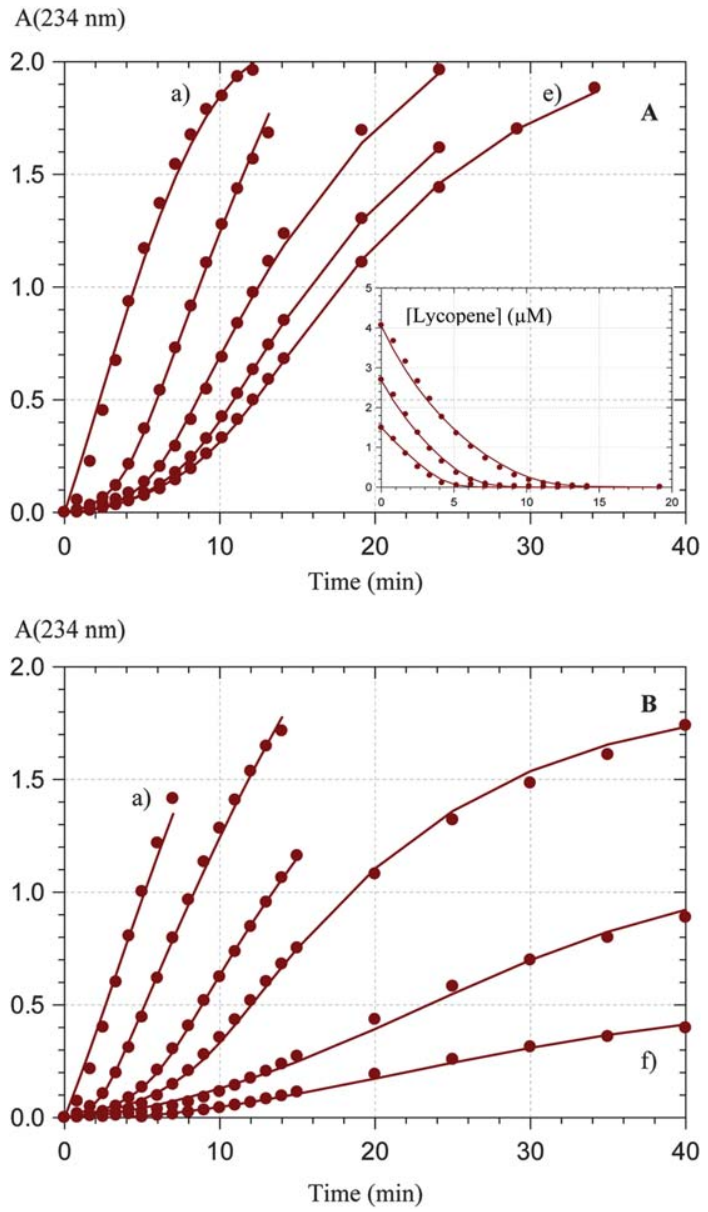

Fig. 2 Inhibition of the metmyoglobin-induced peroxidation of linoleic acid by carotenoids in a pH 5.8 micelle solution. (A) Accumulation of conjugated dienes (monitored by absorbance measurement at $234 \mathrm{~nm}$ ), initial lycopene concentration: 0 (a), 1.5 (b), 2.7 (c), 3.0 (d), 4.1 (e) $\mu \mathrm{M}$. The solid lines are the results of the curve-fitting procedure (see model in Annex 1). Inset: lycopene consumption (initial lycopene concentrations $=1.5,2.7$ and $4.1 \mu \mathrm{M}$ ). The solid lines are the results of simulations using the set of parameters deduced from the curve-fitting procedure shown in part A. (B) Accumulation of conjugated dienes, initial concentration of HU36 carotenoids: 0 (a), 0.8 (b), 1.5 (c), 2.1 (d), 2.9 (e), 3.6 (f) $\mu \mathrm{M}$. The solid lines are the results of the curve-fitting procedures (see model in Annex 1).

plotted as a function of the initial carotenoid concentration (data not shown). Given the slight curvature of the plots, a polynomial relationship was used for the curve-fitting: $T / T_{0}=1+$ $p C+q C^{2}$. The $\mathrm{IC}_{50}$ parameter (in $\mu \mathrm{M}$ ), commonly used to evaluate the antioxidant capacity, is defined as the carotenoid concentration giving a $T$ value twice as large as the control period with no antioxidant. ${ }^{15-17}$ The $\mathrm{IC}_{50}$ parameter can be estimated from the $T / T_{0} v s$. $C$ curves: $\mathrm{IC}_{50}=\left[\sqrt{ }\left(p^{2}+4 q\right)-p\right] /(2 q)$. The lower the $\mathrm{IC}_{50}$ value, the more efficient the antioxidant (Table 1).

When linoleic acid oxidation was initiated by heme iron, bacterial carotenoids from HU36 or GB1 were found to be significantly better antioxidants than the 3 reference carotenoids (Table 1). The pH of the micelle solution only had a low impact on the relative antioxidant capacities of the carotenoids. When oxidation was initiated by $\mathrm{Fe}^{\mathrm{II}}$ (Table 1), purified bacterial carotenoids were no longer better inhibitors than reference carotenoids.

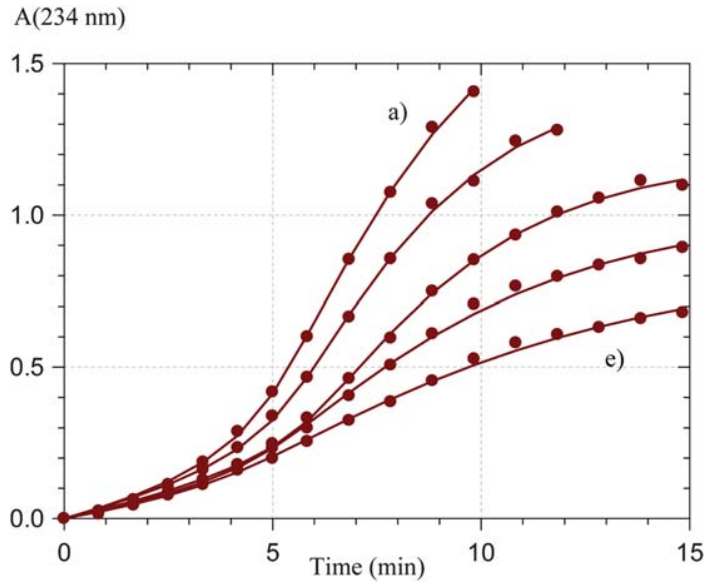

Fig. 3 Accumulation of conjugated dienes during the inhibition of the Fe"induced peroxidation of linoleic acid by HU36 carotenoids in a pH 4 micelle solution. Initial carotenoid concentration: 1.5 (a), 2.2 (b), 3.0 (c), 3.6 (d), 4.4 (e) $\mu \mathrm{M}$. The solid lines are the results of the curve-fitting procedure (see model in Annex 2).

Table $1 \quad I C_{50}$ values for the inhibition of linoleic acid peroxidation by carotenoids in micelles ${ }^{a}$

\begin{tabular}{llll}
\hline Carotenoid & $\begin{array}{l}\mathrm{IC}_{50}(\mu \mathrm{M}) \\
\mathrm{MbFe}^{\mathrm{III}}, \mathrm{pH} 5.8\end{array}$ & $\begin{array}{l}\mathrm{IC}_{50}(\mu \mathrm{M}) \\
\mathrm{MbFe}^{\mathrm{III}}, \mathrm{pH} 4\end{array}$ & $\begin{array}{l}\mathrm{IC}_{50}(\mu \mathrm{M}) \\
\mathrm{Fe}^{\mathrm{II}}, \mathrm{pH} 4\end{array}$ \\
\hline $\begin{array}{llll}\text { L-Carotene } \\
\text { Lycopene }\end{array}$ & $1.92( \pm 0.14)$ & $2.40( \pm 0.12)$ & $3.52( \pm 0.10)$ \\
Astaxanthin & $1.50( \pm 0.03)^{b}$ & $1.66( \pm 0.10)$ & $2.69( \pm 0.26)$ \\
HU36 carotenoids & $0.80( \pm 0.38)$ & $1.37( \pm 0.13)$ & $5.42( \pm 0.18)$ \\
GB1 carotenoids & $0.70( \pm 0.03)$ & $1.27( \pm 0.09)$ & $3.92( \pm 0.08)$ \\
& & $0.78( \pm 0.03)$ & $4.62( \pm 0.09)$
\end{tabular}

${ }^{a}$ From the polynomial fitting of the $T / T_{0} v s$. antioxidant concentration curves. Each $T$ or $T_{0}$ value (period of time required to accumulate a fixed lipid hydroperoxide concentration in the presence or absence of antioxidant) is the mean of 3 independent measurements. Values between brackets are the standard deviations of the fitting procedure. ${ }^{b}$ Linear fitting.

\subsection{Reduction of ferrylmyoglobin by the carotenoids}

When $\mathrm{MbFe}^{\mathrm{III}}$ is treated with $\mathrm{H}_{2} \mathrm{O}_{2}$ (0.5 equiv.) in the absence of an antioxidant, formation of ferrylmyoglobin $\left(\mathrm{MbFe}^{\mathrm{IV}}=\mathrm{O}\right)$ can be observed at $590 \mathrm{~nm} .{ }^{15}$ When an antioxidant is added, a decay of $A(590 \mathrm{~nm})$ occurs if $\mathrm{MbFe}^{\mathrm{IV}}=\mathrm{O}$ is reduced. In the presence of each carotenoid $(100 \mu \mathrm{M})$, the reduction of $\mathrm{MbFe}^{\mathrm{IV}}=\mathrm{O}$ was negligible (indistinguishable from that observed in the control experiment with $\mathrm{MeOH}$ alone, data not shown). Thus, none of the carotenoids tested in this work significantly react with $\mathrm{MbFe}^{\mathrm{IV}}=\mathrm{O}$.

\subsection{Changes in the iron redox state during $\mathrm{Fe}^{\mathrm{II}}$-induced linoleic acid peroxidation}

Except in strongly acidic conditions, $\mathrm{Fe}^{\mathrm{II}}$ is known to be very sensitive to autoxidation. ${ }^{31}$ In the $\mathrm{pH} 4$ solution of linoleic acid micelles without carotenoid, $\mathrm{Fe}^{\mathrm{II}}$ was totally converted into $\mathrm{Fe}^{\mathrm{III}}$ over 20 min (Fig. 4). Moreover, the total iron concentration remained constant over time, confirming that the independent titration methods used are fully reliable. As soon as the conversion of $\mathrm{Fe}^{\mathrm{II}}$ into $\mathrm{Fe}^{\mathrm{III}}$ was complete, saturation in the $\mathrm{CD}$ 
$[\mathrm{Fe}](\mu \mathrm{M})$
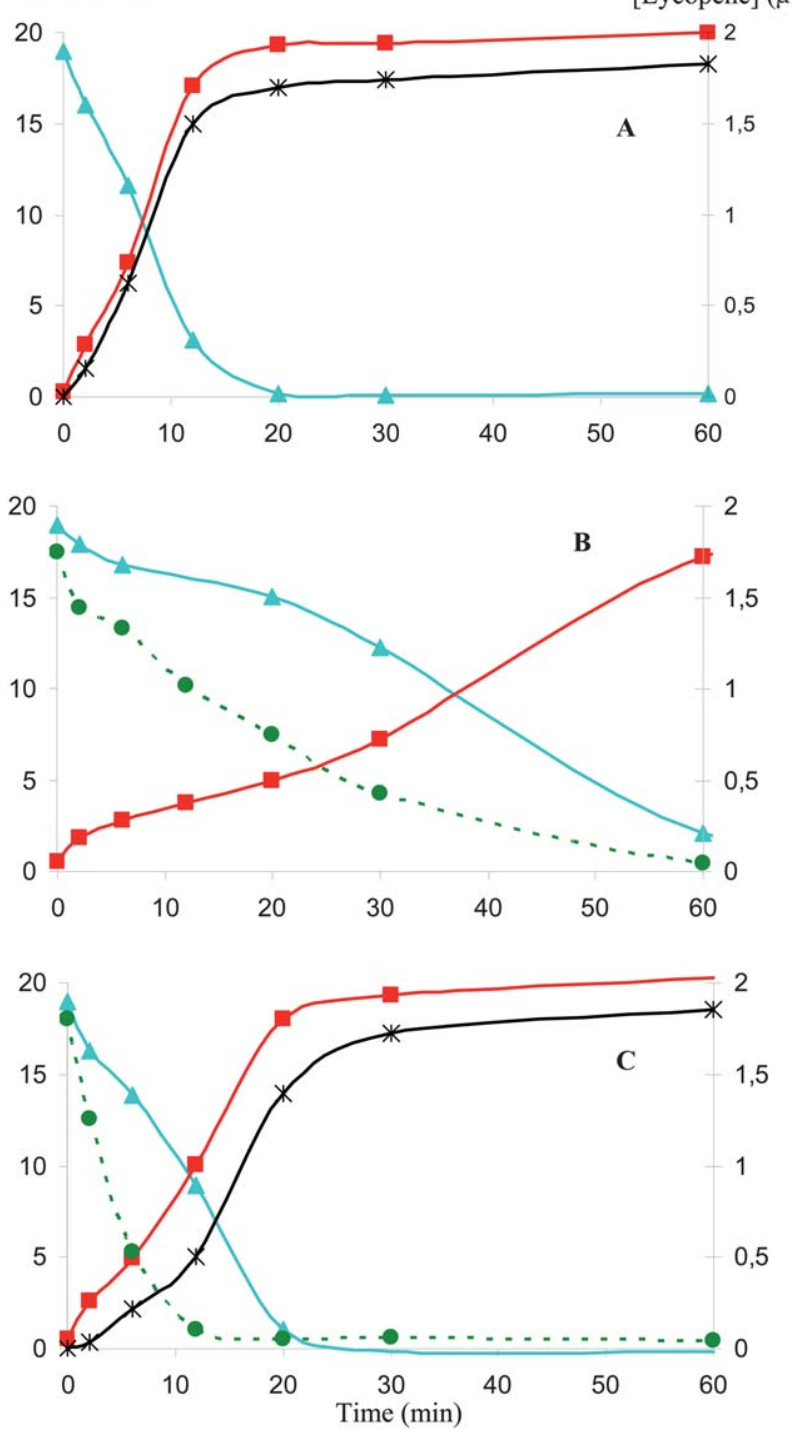

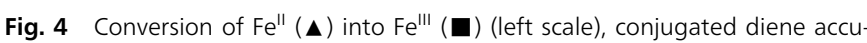
mulation $(*)$ and lycopene consumption (dashed curve, $\mathbf{0}$ ) (right scale) in acetate buffer $\mathrm{pH} 4+$ Brijß35, $37^{\circ} \mathrm{C}$. (A) Fe" + linoleic acid, (B) Fe" + lycopene, (C) Fe" + linoleic acid + lycopene. Initial concentrations $=20 \mu \mathrm{M} \mathrm{Fe",} 0.7 \mathrm{mM}$ linoleic acid, $2 \mu \mathrm{M}$ lycopene.

concentration was observed. In the $\mathrm{pH} 4$ solution of lycopene micelles without linoleic acid, the conversion of $\mathrm{Fe}^{\mathrm{II}}$ into $\mathrm{Fe}^{\mathrm{III}}$ was much slower, suggesting that the carotenoid reduces $\mathrm{Fe}^{\mathrm{III}}$ released in the solution and/or high-valence intermediates involved in $\mathrm{Fe}^{\mathrm{II}}$ autoxidation. ${ }^{31}$ Finally, in the $\mathrm{pH} 4$ solution of micelles containing both linoleic acid and lycopene, the inhibition of $\mathrm{Fe}^{\mathrm{II}}$ autoxidation by lycopene was not observed because of the fast consumption of lycopene by the lipid peroxyl radicals.

\subsection{Characteristics of emulsions}

Analysis by optical microscopy revealed a homogeneous distribution of lipid droplets in emulsions (data not shown). Analysis by laser granulometry indicated that the droplet size fell in the range $0.4-20 \mu \mathrm{m}$ with a major population between 1 and $3 \mu \mathrm{m}$. The droplet diameter $D_{3,2}$ (based on the average surface area) was $1.45( \pm 0.13) \mu \mathrm{m}$. Moreover, emulsions were stable over the whole duration $(6 \mathrm{~h})$ of the kinetic measurements.

Ultracentrifugation of emulsions highlighted marked differences in the partition of carotenoids between the oil and aqueous phases. More than $85 \%$ of astaxanthin and $\beta$-carotene were found in oil, while $c a .70 \%$ of HU36 carotenoids were recovered in the aqueous phase. These results suggest that astaxanthin and $\beta$-carotene are located inside the lipid droplets of the emulsion while HU36 carotenoids lie at the interface. After ultracentrifugation, HU36 carotenoids mainly remain in the aqueous phase, probably as components of phospholipid liposomes.

\subsection{Inhibition of lipid peroxidation by carotenoids in emulsions}

In emulsions, heme-induced lipid peroxidation was much slower than in micelles and higher carotenoid concentrations were necessary to achieve substantial inhibition. With $25 \mu \mathrm{M}$ HU36 carotenoids, the onset of peroxidation was delayed by about $20 \mathrm{~min}$ (Table 2). However, after $3 \mathrm{~h}$, the CD concentration was the same as the one measured in the control (Fig. 5). With higher carotenoid concentrations $(100 \mu \mathrm{M})$, the initiation phase was extended to $90 \mathrm{~min}$. The peroxidation rate during the propagation phase was the same with and without carotenoid. Almost all the carotenoids were consumed during the initiation phase. GB1 carotenoids behaved similarly, but gave shorter initiation phases (Fig. 5).

Unlike the bacterial carotenoids, $\beta$-carotene and lycopene did not produce induction periods, even at high concentrations (Fig. 5). Only astaxanthin induced a slight delay of about $10 \mathrm{~min}$ when added at $100 \mu \mathrm{M}$ (data not shown). Moreover, the 3 reference carotenoids were less consumed than the bacterial carotenoids during the induction phase. In the longer run, residual concentrations of the reference carotenoids seem to provide a persistently weak protection. Consequently, the final CD concentrations $(t=6 \mathrm{~h})$ are close for all carotenoids investigated.

Table 2 Kinetic parameters for the inhibition of sunflower oil peroxidation by carotenoids in emulsions

\begin{tabular}{lccc}
\hline Carotenoid & $C_{0}{ }^{a}(\mu \mathrm{M})$ & $T_{\text {lag }^{b}}(\min )$ & $T_{1 / 2}{ }^{c}(\mathrm{~min})$ \\
\hline Control & - & 5.3 & - \\
$\beta$-Carotene & 32.5 & 7.0 & 240 \\
Lycopene & 100.0 & 6.8 & 305 \\
& 26.9 & 6.7 & 170 \\
Astaxanthin & 93.0 & 7.0 & 95 \\
HU36 carotenoids & 24.4 & 13.4 & 180 \\
\multirow{2}{*}{ GB1 carotenoids } & 84.1 & 20.8 & 85 \\
& 25.1 & 30.0 & 27 \\
& 90.6 & 88.0 & 82 \\
& 24.6 & 15.9 & 25 \\
& 90.9 & 60.6 & 55
\end{tabular}

${ }^{a}$ Initial antioxidant concentration. ${ }^{b}$ Induction period of lipid peroxidation. ${ }^{c}$ Period of time for $50 \%$ antioxidant consumption. 

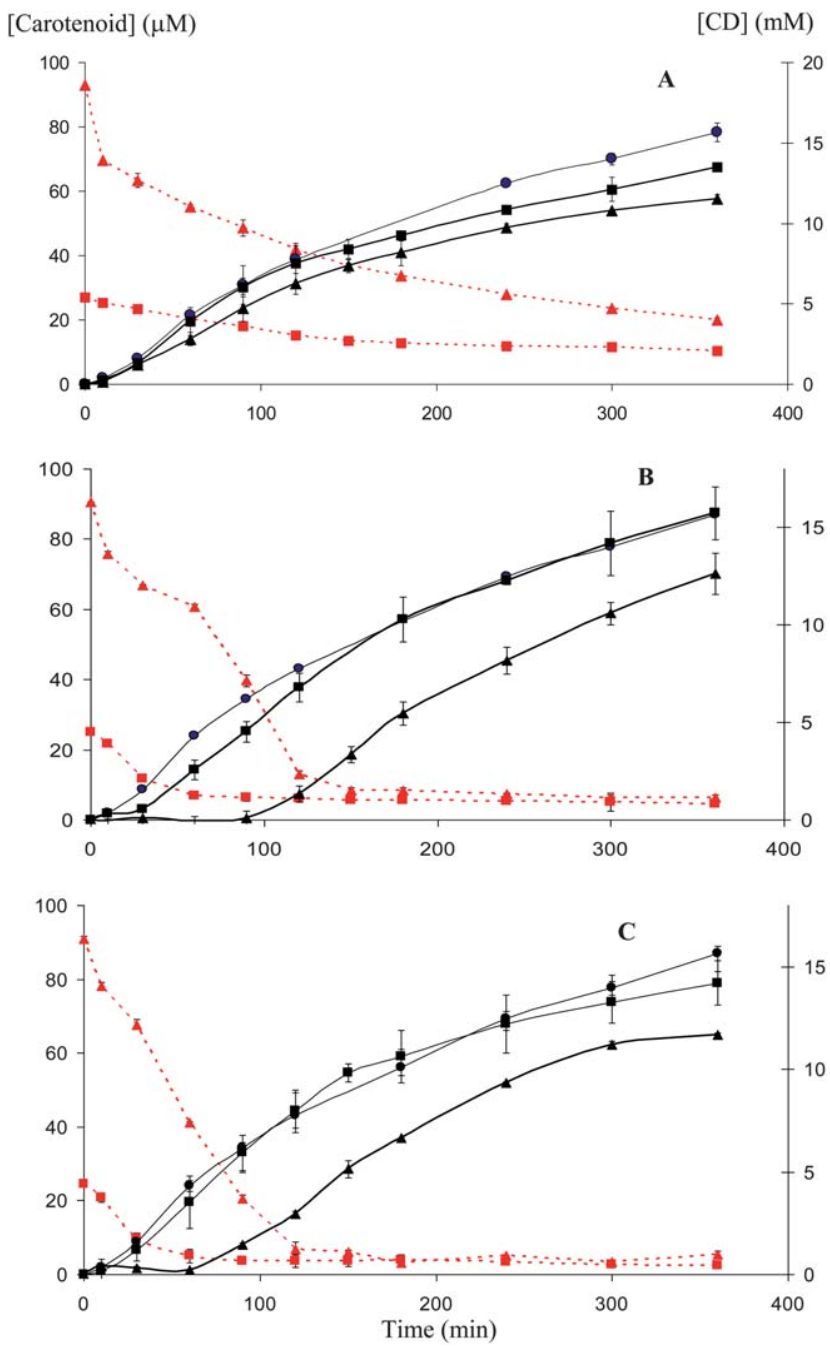

Fig. 5 Inhibition of the metmyoglobin-induced peroxidation of sunflower oil by carotenoids in a pH 4 emulsion stabilized by phospholipids. Plain curves: conjugated diene accumulation (right scale: uninhibited $(\bullet)$ ), inhibited by carotenoids $(\boldsymbol{\square}, \mathbf{\Lambda})$ ). Dashed curves: carotenoid consumption (left scale: $\mathbf{m}, \mathbf{\Delta})$. (A) Lycopene, (B) HU36 carotenoids, (C) GB1 carotenoids, carotenoid concentrations $=0$, 25, $100 \mu \mathrm{M}$. Each point is the mean of three independent measurements, SEM values are reported.

Areas under the curves of $\mathrm{CD}$ accumulation (in $\mathrm{mM} \mathrm{h}$ ) calculated by integration over $6 \mathrm{~h}$ of lipid peroxidation were used as a quantitative indicator to compare the antioxidant activity of the carotenoids (Fig. 6). Statistical ANOVA tests showed that HU36 and GB1 carotenoids were significantly better antioxidants than $\beta$-carotene, lycopene and astaxanthin, which could not be discriminated by their ability to inhibit lipid peroxidation in this model.

\section{Discussion}

Dietary PUFA oxidation products (especially aldehydes) are partially bioavailable and potentially harmful. ${ }^{32}$ They cause oxidative stress and inflammation in intestinal cells ${ }^{33}$ and may be involved in the development of atherosclerosis ${ }^{34}$ and colon cancer. $^{35}$ As dietary PUFA oxidation products may be

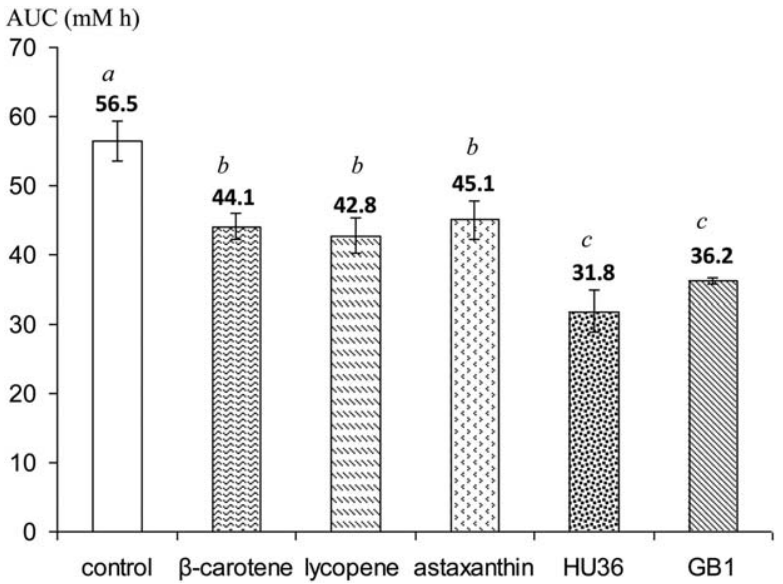

Fig. 6 Inhibition of the metmyoglobin-induced peroxidation of sunflower oil by carotenoids $(100 \mu \mathrm{M})$ in a $\mathrm{pH} 4$ emulsion stabilized by phospholipids during $6 \mathrm{~h}$. Means of 3 independent experiments \pm SD. Different letters indicate significant differences $(p<0.05)$ between means (ANOVA and Tukey-Kramer test).

accumulated not only in food but also in the digestive tract because of the prooxidant activity of dietary iron, investigation of the capacity of dietary antioxidants to fight this specific form of postprandial oxidative stress is of great nutritional importance. $^{36}$

\subsection{Inhibition of $\mathrm{MbFe}^{\mathrm{III}}$-induced lipid peroxidation in micelles}

Hydrolysis of triacylglycerols is initiated in the gastric compartment through the action of the gastric lipase, which can account for $5-30 \%$ of lipid digestion. ${ }^{37}$ Moreover, with a maximal activity at $\mathrm{pH} c a$. 5.4, gastric lipase is especially active during the first hour of gastric digestion when the $\mathrm{pH}$ is often still elevated. Free fatty acids thus released can become primary targets of lipid oxidation. Hence, investigating the oxidation of linoleic acid micelles induced by dietary iron in mildly acidic micelle solutions is a first acceptable model of possible lipid oxidation in the stomach.

The induction period of iron-induced lipid peroxidation was well correlated with the period required for consuming most carotenoids. Induction periods are typical of antioxidants acting in the lipid phase by scavenging the propagating lipid peroxyl radicals (chain-breaking antioxidants). ${ }^{\mathbf{1 6}}$ On the other hand, the selected carotenoids do not reduce ferrylmyoglobin, an easily prepared model peroxidation initiator. ${ }^{15,17}$ This observation suggests that inhibition of initiation is unimportant with these antioxidants. It can be noted that the propagation rate of inhibited peroxidation remained lower than in the control, even if the carotenoids were totally consumed. This trend was more pronounced with the bacterial carotenoids, especially HU36. On the other hand, it is known that the heme cofactor is gradually consumed during lipid peroxidation as evidenced by the decay of the Soret band. ${ }^{\mathbf{1 5 , 1 6}}$ Hence, saturation in $\mathrm{CD}$ accumulation probably reflects a gradual shift from heme-induced lipid peroxidation to a much less efficient mechanism induced by free iron. 
The scavenging of peroxyl radicals by carotenoids can take place by three distinct mechanisms: radical addition onto the conjugated hydrocarbon chain, electron transfer with formation of carotenoid radical cations and abstraction of labile allylic $\mathrm{H}$-atoms with formation of neutral radicals, the latter mechanism being probably minor. ${ }^{38,39}$ While the first two mechanisms can take place in polar media including micelle solutions and microemulsions, only the first mechanism is observed in media of low polarity.

The carotenoids investigated include the hydrocarbons lycopene and $\beta$-carotene, the xanthophyll astaxanthin (ketocarotenoid) and the bacterial carotenoids from HU36 and GB1 (carotenoid glycosides and glycosylesters). Based on the $\mathrm{IC}_{50}$ values, the bacterial carotenoids from HU36 or GB1 were found to be significantly better antioxidants than the reference pigments. This efficiency of carotenoids at inhibiting lipid peroxidation is governed by a combination of factors: ${ }^{38,39}$ (a) the intrinsic ability of carotenoids to deliver electrons (low ionization potential) and/or form stabilized radical adducts (by electron delocalization through the polyene chain), (b) the partition of carotenoids between lipid phase and interface depending on the presence of polar terminal groups (carotenes vs. xanthophylls and glycosyl carotenoids), (c) the sensitivity of carotenoids to iron-induced autoxidation, ${ }^{40}$ which may lower the actual concentration of carotenoids available for the scavenging of lipid peroxyl radicals, (d) the ability of carotenoid-derived radicals to react with $\mathrm{O}_{2}$, thereby forming peroxyl radicals that may propagate lipid peroxidation (prooxidant effect) and (e) the residual redox activity of carotenoid oxidation products (e.g., aldehydes and ketones, carboxylic acids, epoxides).$^{17}$

From a simplified scheme of heme-induced lipid peroxidation (Scheme 2) and using a refined mathematical treatment adapted from our previous works (see details in Annex 1), we were able to carry out curve-fitting experiments on the experimental plots expressing the time dependence of CD accumulation. From the general mechanism of heme-induced lipid peroxidation, the following parameters can be defined: the rate constant $k_{\mathrm{i} 1}$ of lipid hydroperoxide (LOOH) cleavage by heme$\mathrm{Fe}^{\mathrm{III}}$ (first initiation step) with concomitant formation of heme$\mathrm{Fe}^{\mathrm{IV}}$, a parameter $\left(r_{2}\right)$ expressing the oxidizability of linoleic acid $(\mathrm{LH})$ in the medium and combining the propagation and termination rate constants, a dimensionless parameter $\left(\mathrm{AE}_{2}\right)$ expressing the competition between the antioxidant and lipid for the propagating peroxyl radicals (LOO), a dimensionless

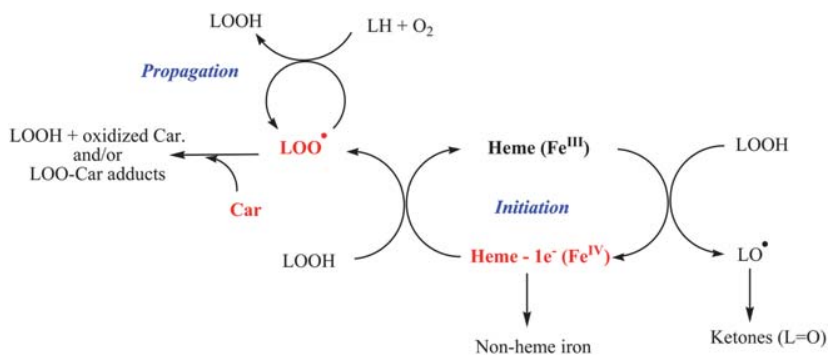

Scheme 2 Proposed mechanism of the metmyoglobin-induced peroxidation of linoleic acid ( $\mathrm{LH}$ ) and inhibition by carotenoids (Car). parameter $\left(\mathrm{AE}_{1}\right)$ expressing the competition between the antioxidant and $\mathrm{LOOH}$ for heme-Fe ${ }^{\mathrm{IV}}$, a parameter $\left(C_{\mathrm{d}}\right)$ measuring the degradation of heme-Fe ${ }^{\mathrm{IV}}$ into inert metal species (in competition with its reaction with $\mathrm{LOOH}$ to produce LOO), and the antioxidant stoichiometry $(n)$ defined as the number of oxidizing equivalents (heme-Fe ${ }^{\mathrm{IV}}$ and/or LOO) trapped per antioxidant molecule. Quite satisfactory curve-fittings (typically, $r>$ 0.999, see Fig. 2A and B) were obtained from the experimental CD concentration $v s$. time plots. Parameters $k_{\mathrm{i} 1}$ and $r_{2}$ were first determined in the absence of an antioxidant and used for subsequent estimation of the other parameters in the presence of given antioxidant concentrations (Tables 3 and 4). In all calculations, parameter $\mathrm{AE}_{1}$ could be set to zero, in agreement with carotenoids acting as chain-breaking antioxidants by scavenging LOO (inhibition of propagation) instead of reducing heme-Fe $\mathrm{FV}^{\mathrm{IV}}$ (inhibition of initiation). As an additional control, sets of optimized parameters allowed us to construct theoretical curves for antioxidant consumption that were in good agreement with the experimental curves (see Fig. 2A, inset).

As shown in the case of lycopene and the bacterial carotenoids, $\mathrm{AE}_{2}$ values of the order of 100 were obtained meaning that the reaction of the propagating peroxyl radicals with the carotenoids is faster by 2 orders of magnitude than the corresponding reaction with linoleic acid. Moreover, the $n$ values suggest that the carotenoids can trap 2-3 LOO radicals before being converted into inert oxidation products. At first sight, close $\mathrm{AE}_{2}$ and $n$ values for all the carotenoids could seem to be in contradiction to the overall higher antioxidant efficiency of the bacterial carotenoids compared with the reference pigments. It must however be stressed that the peroxidation curves are highly sensitive to both parameters, especially $n$, as shown in simulations in which all other parameters are set constant (Fig. 7). In particular, a shift from $n=2$ to $n=3$ promotes a huge slowing down of the peroxidation provided that heme degradation is taken into account. It can thus be proposed that the higher potency of the bacterial carotenoids mainly reflects their ability to scavenge $c a$. one more lipid peroxyl radical than the reference carotenoids.

With the exception of the yellow components of HU36, the bacterial carotenoids display polyene chain conjugated with one or two electron-withdrawing carboxyl group(s) (Scheme 1). Similarly, the polyene chain of astaxanthin is conjugated with two keto groups. This conjugation is expected to lower the electron-donating capacity. This is confirmed by the values of ionization potentials $\left(I_{\mathrm{p}}\right): I_{\mathrm{p}}=5.1 \mathrm{eV}$ for $\beta$-carotene $v s .5 .7 \mathrm{eV}$ for astaxanthin..$^{41}$ By contrast, the one-electron reduction potentials of radical cations in aqueous micellar solution turned out to be very close (in the range $1020 \pm 40 \mathrm{mV}$ ) for carotenes and xanthophylls, including $\beta$-carotene and astaxanthin..$^{\mathbf{4 2}} \mathrm{A}$ plausible explanation is that xanthophylls are more exposed to the aqueous phase (via solvation of their polar terminal groups) and thus more readily involved in electron transfer reactions despite their intrinsically lower oxidizability. Anyway, the one-electron reduction potentials of carotenoid radical cations (ca. $1 \mathrm{~V}$ ) are much higher than the ones of lipid peroxyl radicals $(c a .0 .7 \mathrm{~V}$ ), thus making unlikely a direct electron transfer from carotenoids to lipid peroxyl radicals. ${ }^{39}$ Consequently, inhibition of lipid 
Table 3 Kinetic parameters for the inhibition of the metmyoglobin-induced peroxidation of linoleic acid by carotenoids in micelles ( $\mathrm{pH}$ 5.8)

\begin{tabular}{|c|c|c|c|c|c|}
\hline $\mathrm{Car} / \mu \mathrm{M}$ & $r_{2} / \mathrm{M}^{-1 / 2} \mathrm{~s}^{-1 / 2}$ & $k_{\mathrm{i} 1} / \mathrm{M}^{-1} \mathrm{~s}^{-1}$ & $\mathrm{AE}_{2}$ & $n$ & $C_{\mathrm{d}} / \mu \mathrm{M}$ \\
\hline \multicolumn{6}{|c|}{ Lycopene } \\
\hline 0 & $1.77( \pm 0.02)$ & $2610( \pm 150)$ & - & - & 0 \\
\hline 2.7 & 1.77 & 2610 & $108( \pm 15)$ & $2.2( \pm 0.1)$ & $1.24( \pm 0.02)$ \\
\hline 3.0 & 1.77 & 2610 & $85( \pm 1)$ & $2.4( \pm 0.1)$ & $1.19( \pm 0.01)$ \\
\hline 3.4 & 1.77 & 2610 & $72( \pm 2)$ & $2.4( \pm 0.1)$ & $1.13( \pm 0.01)$ \\
\hline 4.1 & 1.77 & 2610 & $97( \pm 8)$ & $1.9( \pm 0.1)$ & $1.16( \pm 0.02)$ \\
\hline \multicolumn{6}{|l|}{ HU36 } \\
\hline 0 & 1.70 & $1810( \pm 230)$ & - & - & 0 \\
\hline 1.5 & 1.70 & 1810 & $114( \pm 6)$ & $2.9( \pm 0.1)$ & $1.62( \pm 0.03)$ \\
\hline 2.1 & 1.70 & 1810 & $98( \pm 9)$ & $2.5( \pm 0.1)$ & $1.66( \pm 0.02)$ \\
\hline 2.9 & 1.70 & 1810 & $66( \pm 7)$ & $2.9( \pm 0.2)$ & $1.32( \pm 0.07)$ \\
\hline 3.6 & 1.70 & 1810 & $69( \pm 8)$ & $3.0( \pm 0.3)$ & $1.06( \pm 0.07)$ \\
\hline \multicolumn{6}{|l|}{ GB1 } \\
\hline 0 & $1.98( \pm 0.02)$ & $2380( \pm 340)$ & - & - & 0 \\
\hline 1.8 & 1.98 & 2380 & $108( \pm 12)$ & $2.3( \pm 0.1)$ & $1.54( \pm 0.02)$ \\
\hline 2.5 & 1.98 & 2380 & $133( \pm 10)$ & $2.0( \pm 0.1)$ & $1.62( \pm 0.01)$ \\
\hline 3.1 & 1.98 & 2380 & $96( \pm 6)$ & $2.2( \pm 0.1)$ & $1.43( \pm 0.02)$ \\
\hline 3.6 & 1.98 & 2380 & $131( \pm 16)$ & $1.9( \pm 0.1)$ & $1.33( \pm 0.03)$ \\
\hline
\end{tabular}

Table 4 Kinetic parameters for the inhibition of the metmyoglobin-induced peroxidation of linoleic acid by carotenoids in micelles ( $\mathrm{pH} 4.0)^{a}$

\begin{tabular}{|c|c|c|c|c|c|}
\hline $\mathrm{Car} / \mu \mathrm{M}$ & $r_{2} / \mathrm{M}^{-1 / 2} \mathrm{~s}^{-1 / 2}$ & $k_{\mathrm{i} 1} / \mathrm{M}^{-1} \mathrm{~s}^{-1}$ & $\mathrm{AE}_{2}$ & $n$ & $C_{\mathrm{d}} / \mu \mathrm{M}$ \\
\hline \multicolumn{6}{|c|}{ Lycopene } \\
\hline 0 & $1.51( \pm 0.03)$ & $3000( \pm 480)$ & - & - & 0 \\
\hline 2.7 & 1.51 & 3000 & $187( \pm 63)$ & $1.6( \pm 0.1)$ & $1.40( \pm 0.01)$ \\
\hline 3.1 & 1.51 & 3000 & $127( \pm 7)$ & $1.6( \pm 0.1)$ & $1.37( \pm 0.01)$ \\
\hline 3.7 & 1.51 & 3000 & $80( \pm 7)$ & $1.9( \pm 0.1)$ & $1.28( \pm 0.02)$ \\
\hline 4.2 & 1.51 & 3000 & $100( \pm 7)$ & $1.9( \pm 0.1)$ & $1.07( \pm 0.01)$ \\
\hline \multicolumn{6}{|l|}{ HU36 } \\
\hline 0 & 1.7 & $2530( \pm 630)$ & - & - & 0 \\
\hline 1.5 & 1.7 & 2530 & $152( \pm 14)$ & $3.4( \pm 0.1)$ & $1.73( \pm 0.03)$ \\
\hline 2.2 & 1.7 & 2530 & $86( \pm 7)$ & $4.3( \pm 0.1)$ & $1.43( \pm 0.03)$ \\
\hline 2.9 & 1.7 & 2530 & $40( \pm 7)$ & $7.1( \pm 0.8)$ & $0.80( \pm 0.07)$ \\
\hline \multicolumn{6}{|l|}{ GB1 } \\
\hline 0 & $1.60( \pm 0.02)$ & $3420( \pm 180)$ & - & - & 0 \\
\hline 2.5 & 1.60 & 3420 & $102( \pm 10)$ & $2.3( \pm 0.1)$ & $1.37( \pm 0.01)$ \\
\hline 2.9 & 1.60 & 3420 & $62( \pm 7)$ & $3.4( \pm 0.2)$ & $1.03( \pm 0.03)$ \\
\hline 4.2 & 1.60 & 3420 & $74( \pm 6)$ & $2.9( \pm 0.2)$ & $0.84( \pm 0.03)$ \\
\hline
\end{tabular}

${ }^{a}$ From the mathematical analysis of the $A(234 \mathrm{~nm}) v s$. time curves according to the model developed in Annex $1(r>0.995)$. Values between brackets are the standard deviations of the curve-fitting procedure. See Annex 1 for complete definition of parameters: $r_{2}=$ lipid oxidizability, $k_{\mathrm{i} 1}=$ rate constant for lipid hydroperoxide cleavage, $\mathrm{AE}_{2}=$ antioxidant efficiency for inhibition of propagation, $n=$ antioxidant stoichiometry, $C_{\mathrm{d}}=$ heme degradation parameter.

peroxidation probably occurs via peroxyl radical addition on the polyene chain and, based on the close $\mathrm{AE}_{2}$ values (Tables 3 and 4 ), this reaction seems only weakly influenced by the carotenoid structure (although compensating effects may also operate as in electron transfer).

Finally, it must also be stressed that, being mixtures of several carotenoids, the GB1 and HU36 purified extracts may also benefit from some synergistic interplay between their components.

\subsection{Inhibition of $\mathrm{MbFe}^{\mathrm{III}}$-induced lipid peroxidation in emulsions}

For its significance in terms of food stability, lipid peroxidation in oil-in-water emulsions has been extensively investigated ${ }^{\mathbf{4 3 , 4 4}}$ 


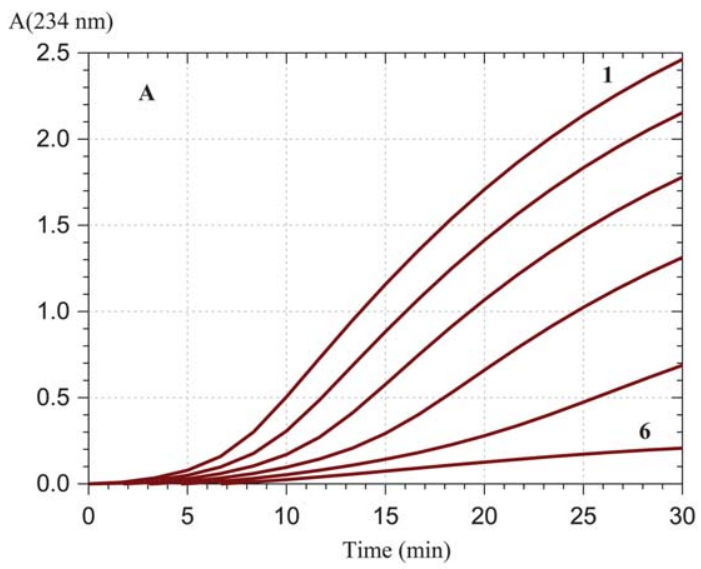

$\mathrm{A}(234 \mathrm{~nm})$

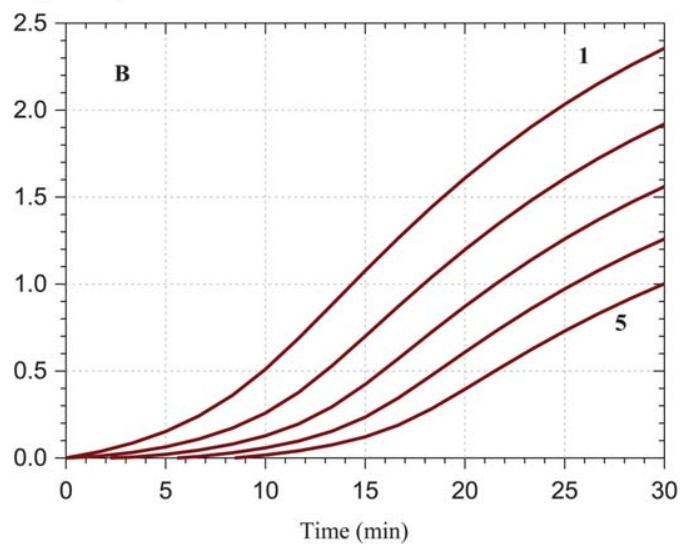

Fig. 7 Inhibition of the metmyoglobin-induced peroxidation of linoleic acid in a pH 5.8 micelle solution. Simulations using $r_{2}=1.8 \mathrm{M}^{-1 / 2} \mathrm{~s}^{-1 / 2}, k_{\mathrm{i} 1}=2 \times 10^{3} \mathrm{M}^{-1}$ $\mathrm{s}^{-1}, \mathrm{C}_{\mathrm{d}}=1.2 \mu \mathrm{M}$, antioxidant concentration $=3 \mu \mathrm{M}$. (A) $\mathrm{AE}_{2}=100, n=2.0$ (curve 1), 2.2, 2.4, 2.6, 2.8, 3.0 (curve 6). (B) $n=2.5, \mathrm{AE}_{2}=50$ (curve 1), $75,100,125,150$ (curve 5).

in addition to its inhibition by food antioxidants including carotenoids. ${ }^{45}$ In our previous works, ${ }^{18,19}$ sunflower oil-in-water emulsions stabilized by phospholipids proved valuable models for investigating lipid peroxidation induced by dietary iron in the stomach and were thus selected for this study.

The hierarchy emerging from the simple micelle model (bacterial carotenoids > reference carotenoids) was translated into the more elaborated sunflower oil-in-water emulsion model. Thus, when added in a sufficient concentration $(100 \mu \mathrm{M})$, the HU36 and GB1 carotenoids were efficient chainbreaking antioxidants in the emulsion model giving welldefined induction periods while the reference carotenoids barely reduced the peroxidation rate with no significant lag phase (Fig. 5). As the bacterial carotenoids have a much higher affinity for the aqueous phase of the emulsion than the reference carotenoids, it may be suggested that the location of the HU36 and GB1 carotenoids close to the interface favors the scavenging of the lipid peroxyl radicals, themselves produced at the interface by reaction between hypervalent heme iron and the lipid hydroperoxides.

Taking a total concentration of linoleic acid residues of $c a$. $250 \mathrm{mM}$ in the emulsions (based on the sunflower oil and
Table 5 Kinetic parameters for the inhibition of the metmyoglobin-induced peroxidation of linoleic acid by carotenoids in emulsions $(\mathrm{pH} 4.0)^{a}$

\begin{tabular}{lllll}
\hline Carotenoid $^{b}$ & $10^{3} r_{2} / \mathrm{M}^{-1 / 2} \mathrm{~s}^{-1 / 2}$ & $k_{\mathrm{i} 1} / \mathrm{M}^{-1} \mathrm{~s}^{-1}$ & $\mathrm{AE}_{2}$ & $n$ \\
\hline Control & $12.2( \pm 0.2)$ & $2.0( \pm 0.1)$ & - & - \\
Lycopene & $10.8( \pm 0.1)$ & $2.3( \pm 0.1)$ & - & - \\
HU36 carotenoids & 12 & 2 & $660( \pm 390)$ & $7( \pm 1)$ \\
GB1 carotenoids & 12 & 2 & $210( \pm 120)$ & $8( \pm 2)$
\end{tabular}

${ }^{a}$ From the mathematical analysis of the $A(234 \mathrm{~nm}) v s$. time curves according to the model developed in Annex $1(r>0.995)$. Values between brackets are the standard deviations of the curve-fitting procedure. See Annex 1 for complete definition of parameters: $r_{2}=$ lipid oxidizability, $k_{\mathrm{i} 1}=$ rate constant for lipid hydroperoxide cleavage, $\mathrm{AE}_{2}=$ antioxidant efficiency for inhibition of propagation, $n=$ antioxidant stoichiometry. ${ }^{b}$ Initial carotenoid concentration: $100 \mu \mathrm{M}$.

soybean lecithin compositions), it was possible to analyze the peroxidation curves with the same model as in micelles (Table 5). As expected, the oxidizability of linoleic acid residues within the lipid droplets $\left(r_{2} \approx 0.01 \mathrm{M}^{-1 / 2} \mathrm{~s}^{-1 / 2}\right)$ is much lower than for free linoleic acid in micelles $\left(r_{2} \approx 2 \mathrm{M}^{-1 / 2} \mathrm{~s}^{-1 / 2}\right)$ and the same trend is observed for the rate constant of initiation: $k_{\mathrm{i} 1} \approx$ $2 \mathrm{M}^{-1} \mathrm{~s}^{-1}$ in emulsions vs. ca. $3 \times 10^{3} \mathrm{M}^{-1} \mathrm{~s}^{-1}$ in micelles $(\mathrm{pH}$ 4). The difference in $r_{2}$ values indicates that the propagation of lipid peroxidation is much less efficient within the lipid droplets of the emulsions due to the much slower diffusion of the lipid peroxyl radicals. It is also clear that the homolytic cleavage of lipid hydroperoxides by heme iron (rate constant $k_{\mathrm{i} 1}$ ) in emulsions is severely hindered by the limited access of lipid hydroperoxides to the heme at the interface. It must however be noted that the modelling does not discriminate between lipid hydroperoxides derived from triacylglycerols or from phospholipids. The small fraction of interfacial phospholipid hydroperoxides (ca. $3 \%$ in our conditions ${ }^{18}$ ) may well react with metmyoglobin much more rapidly than accounted for by the low $k_{\mathrm{i} 1}$ value.

As evidenced by the absence of lag phase, standard carotenoids only marginally affect the peroxidation curves and consistently are slowly consumed. By contrast, bacterial carotenoids at $100 \mu \mathrm{M}$ induce a well-defined lag phase and the corresponding curves can be satisfactorily analyzed by using the $r_{2}$ and $k_{\mathrm{i} 1}$ parameters determined in uninhibited peroxidation, with $\mathrm{AE}_{2}$ and $n$ as the sole adjustable parameters (heme degradation neglected). The $n$ values thus determined are typically higher than in micelles, which points to an extensive oxidative degradation of bacterial carotenoids in emulsions.

\subsection{Inhibition of $\mathrm{Fe}^{\mathrm{II}}$-induced lipid peroxidation in micelles}

The mechanism is initiated by the homolytic cleavage of lipid hydroperoxides ( $\mathrm{LOOH}$ ) by $\mathrm{Fe}^{\mathrm{II}}$ with the subsequent formation of $\mathrm{Fe}^{\mathrm{III}}$ and LO (Fenton reaction, see Scheme 3 ). ${ }^{46}$ However, the reaction between $\mathrm{Fe}^{\mathrm{III}}$ and $\mathrm{LOOH}$ leading to the propagating LOO radicals and regenerating $\mathrm{Fe}^{\mathrm{II}}$ is very slow, so that the peroxidation essentially stops after total conversion of $\mathrm{Fe}^{\mathrm{II}}$ into $\mathrm{Fe}^{\mathrm{III}}$ (Fig. 4). In this model, carotenoids are expected to express their antioxidant activity by scavenging the initiating LO radicals (or radicals derived therefrom) and propagating LOO radicals. However, their ability to maintain high $\mathrm{Fe}^{\mathrm{II}}$ 


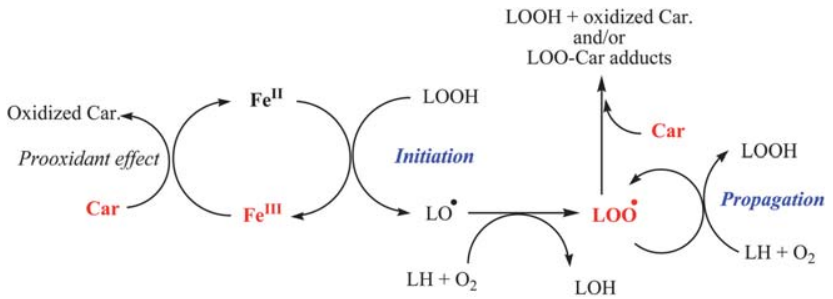

Scheme 3 Proposed mechanism of the Fe"-induced peroxidation of linoleic acid (LH) and inhibition by carotenoids (Car).

concentrations in the solution (Fig. 4) can be considered as an underlying prooxidant effect. Based on the $\mathrm{IC}_{50}$ values (Table 1 ), the bacterial carotenoids are relatively modest inhibitors of the $\mathrm{Fe}^{\mathrm{II}}$-induced peroxidation of linoleic acid and even somewhat less protective than the reference carotenoids.

The mathematical treatment developed for heme-induced lipid peroxidation (Annex 1) was adapted to peroxidation initiated by non-heme iron (Annex 2) and was simply applied to the HU36 carotenoids as an example. Here again, excellent curvefittings were obtained (Fig. 3) as well as consistent values for the $r_{2}$ and $\mathrm{AE}_{2}$ parameters, which must be essentially independent of the initiator (compare Tables 6 with 4). By contrast, the cleavage of lipid hydroperoxides by $\mathrm{Fe}^{\mathrm{II}}$ appears much slower than by $\mathrm{MbFe}^{\mathrm{III}}$ (a factor of ca. 30). Also the antioxidant stoichiometry was surprisingly higher than in heme-induced lipid peroxidation. It must however be stressed that the scavenging of lipid-derived radicals distinct from LOO was not taken into account in this model, nor was the ability of carotenoids to extend the half-life of $\mathrm{Fe}^{\mathrm{II}}$ (Fig. 4). By maintaining larger concentrations of the prooxidant $\mathrm{Fe}^{\mathrm{II}}$ form in the medium (thereby delaying saturation in LOOH accumulation), carotenoids appear less efficient at inhibiting lipid peroxidation initiated by non-heme ( $v s$. heme) iron.

The higher efficiency of the bacterial carotenoids ( $v s$. the reference carotenoids) as inhibitors of heme-induced lipid peroxidation was at least partially ascribed to their easier access

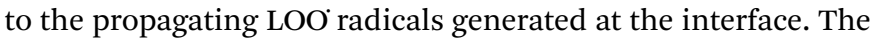
interfacial location of the bacterial carotenoids could also favor the recycling of free $\mathrm{Fe}^{\mathrm{II}}$ and thus the initiation of lipid peroxidation. These compensating effects could explain why the

Table 6 Kinetic parameters for the inhibition of the Fe"-induced peroxidation of linoleic acid by HU36 carotenoids in micelles $\left(\mathrm{pH} \mathrm{4.0)^{a }}\right.$

\begin{tabular}{llllr}
\hline $\operatorname{Car} / \mu \mathrm{M}$ & $r_{2} / \mathrm{M}^{-1 / 2} \mathrm{~s}^{-1 / 2}$ & $k_{\mathrm{i}} / \mathrm{M}^{-1} \mathrm{~s}^{-1}$ & \multicolumn{1}{c}{$\mathrm{AE}_{2}$} & \multicolumn{1}{l}{$n$} \\
\hline 0.8 & $1.8( \pm 0.1)$ & $103( \pm 9)$ & $86( \pm 4)$ & $13.9( \pm 1.1)$ \\
1.5 & $2.0( \pm 0.1)$ & $120( \pm 16)$ & $107( \pm 7)$ & $8.9( \pm 0.9)$ \\
2.2 & $2.0( \pm 0.2)$ & $142( \pm 13)$ & $128( \pm 8)$ & $7.4( \pm 0.4)$ \\
3.0 & $1.7( \pm 0.1)$ & $135( \pm 8)$ & $153( \pm 8)$ & $5.7( \pm 0.2)$ \\
3.6 & $1.1( \pm 0.1)$ & $103( \pm 6)$ & $174( \pm 34)$ & $4.0( \pm 0.3)$
\end{tabular}

${ }^{a}$ From the mathematical analysis of the $A(234 \mathrm{~nm}) v s$. time curves according to the model developed in Annex $2(r>0.995)$. Values between brackets are the standard deviations of the curve-fitting procedure. See Annexes $1 \& 2$ for complete definition of parameters: $r_{2}=$ lipid oxidizability, $k_{\mathrm{i}}=$ rate constant for lipid hydroperoxide cleavage, $\mathrm{AE}_{2}=$ antioxidant efficiency for inhibition of propagation, $n=$ antioxidant stoichiometry. bacterial and reference carotenoids are roughly as potent at inhibiting lipid peroxidation initiated by non-heme iron.

\section{Conclusion}

The carotenoids from newly identified spore-forming pigmented marine bacteria, Bacillus indicus HU36 and Bacillus firmus GB1 are better inhibitors of heme-induced lipid peroxidation in mildly acidic conditions than common carotenoids, possibly because of their location closer to the interface of micelles and lipid droplets. Our quantitative analysis suggests that this improved protection is manifested by a higher number of lipid peroxyl radicals being scavenged by the bacterial carotenoids. Thus, in addition to their potential development as food colorants and dietary supplements endowed with probiotic properties, HU36 and GB1 bacteria may be valuable sources of carotenoid antioxidants protecting against adverse oxidation reactions in the stomach that may participate in the postprandial oxidative stress ${ }^{47}$ (e.g., resulting from excessive ingestion of lipids, sugars and prooxidant species like iron) and its deleterious consequences in terms of cardiovascular health.

\section{Annex 1: mathematical treatment for the inhibition of heme-induced lipid peroxidation}

The reactions involved in the heme-induced peroxidation of linoleic acid in the presence of an antioxidant are summed up below with the corresponding rate constants $\left(\mathrm{M}^{n}\right.$ : low-valence heme, $\mathbf{M}^{n+1}$ : high-valence heme, LH: PUFA, LOOH: PUFA hydroperoxide, $\mathrm{AH}$ : antioxidant):

Initiation

$$
\begin{gathered}
\mathrm{M}^{n}+\mathrm{LOOH} \rightarrow \mathrm{M}^{n+1}+\mathrm{LO}, k_{\mathrm{i} 1} \\
\mathrm{LO} \rightarrow \mathrm{L}=\mathrm{O}+\text { other inert products } \\
\mathrm{M}^{n+1}+\mathrm{LOOH} \rightarrow \mathrm{M}^{n}+\mathrm{LOO}, k_{\mathrm{i} 2} \\
\mathrm{M}^{n+1} \rightarrow \text { inert metal species, } k_{\mathrm{d}}
\end{gathered}
$$

Propagation

$$
\mathrm{LOO}+\mathrm{LH}+\mathrm{O}_{2} \rightarrow \mathrm{LOOH}+\mathrm{LOO}, k_{2}
$$

Termination

$$
\text { 2LOO } \rightarrow \text { non-radical products, } k_{\mathrm{t}}
$$

Inhibition of initiation

$$
\mathrm{M}^{n+1}+\mathrm{AH} \rightarrow \mathrm{M}^{n}+\mathrm{A}, k_{\mathrm{a} 1}
$$

Inhibition of propagation 


$$
\mathrm{LOO}+\mathrm{AH} \rightarrow \mathrm{LOOH}+\mathrm{A}, k_{\mathrm{a} 2}
$$

In the absence of lipid hydroperoxides, it has been shown that ferrylmyoglobin $\left(\mathrm{Fe}^{\mathrm{IV}}\right)$ is unable to initiate the peroxidation of linoleic acid in micelles. ${ }^{48}$ Hence, a direct reaction between $\mathrm{LH}$ and $\mathrm{M}^{n+1}$ is not taken into account. Moreover, LO and derived radicals are assumed not to take part in the initiation step.

The peroxidation rate can be written as:

$$
\begin{gathered}
R_{\mathrm{p}}=\mathrm{d}(\mathrm{LOOH}) / \mathrm{d} t=k_{2}(\mathrm{LOO})(\mathrm{LH})+k_{\mathrm{a} 2}(\mathrm{LOO})(\mathrm{AH}) \\
-k_{\mathrm{i} 1}(\mathrm{LOOH})\left(\mathrm{M}^{n}\right)-k_{\mathrm{i} 2}(\mathrm{LOOH})\left(\mathrm{M}^{n+1}\right)=R_{2}+R_{\mathrm{a} 2}-R_{\mathrm{i} 1}-R_{\mathrm{i} 2}
\end{gathered}
$$

The rate of lipid consumption is: $-\mathrm{d}(\mathrm{LH}) / \mathrm{d} t=R_{2}$

The rate of antioxidant consumption is: $R_{\mathrm{a}}=-\mathrm{d}(\mathrm{AH}) / \mathrm{d} t=$ $R_{\mathrm{a} 1}+R_{\mathrm{a} 2}$

We have: $R_{\mathrm{a} 1}=\frac{R_{\mathrm{i} 2} \mathrm{AE}_{1}(\mathrm{AH})}{(\mathrm{LOOH})}$ with $\mathrm{AE}_{1}=k_{\mathrm{a} 1} / k_{\mathrm{i} 2}$ (antioxidant efficiency at inhibiting inhibition)

Assuming a steady-state for the lipid peroxyl radicals, we may write:

$$
R_{\mathrm{i} 2}=k_{\mathrm{a} 2}(\mathrm{LOO})(\mathrm{AH})+2 k_{\mathrm{t}}\left(\mathrm{LOO}^{\prime}\right)^{2}
$$

Solving for (LOO) gives:

$$
\left(\mathrm{LOO}^{\prime}\right)=\frac{k_{\mathrm{a} 2}(\mathrm{AH})}{4 k_{\mathrm{t}}}\left[\left(1+\frac{8 k_{\mathrm{t}} R_{\mathrm{i} 2}}{k_{\mathrm{a} 2}{ }^{2}(\mathrm{AH})^{2}}\right)^{1 / 2}-1\right]
$$

Hence, we deduce:

$$
R_{\mathrm{a} 2}=k_{\mathrm{a}}(\mathrm{AH})^{2}\left[\left(1+\frac{2 R_{\mathrm{i} 2}}{k_{\mathrm{a}}(\mathrm{AH})^{2}}\right)^{1 / 2}-1\right]
$$

with $k_{\mathrm{a}}=k_{\mathrm{a} 2}^{2} /\left(4 k_{\mathrm{t}}\right)$

We also have: $R_{2}=\frac{R_{a 2}(\mathrm{LH})}{\mathrm{AE}_{2}(\mathrm{AH})}$ with $\mathrm{AE}_{2}=k_{\mathrm{a} 2} / k_{2}$ (antioxidant efficiency at inhibiting propagation).

Assuming a steady-state for $\mathbf{M}^{n+1}$ (hypervalent iron), we deduce: $R_{\mathrm{i} 1}=R_{\mathrm{i} 2}+R_{\mathrm{a} 1}+k_{\mathrm{d}}\left(\mathrm{M}^{n+1}\right)$

This relationship can be written as: $k_{\mathrm{i} 1}(\mathrm{LOOH})\left(\mathrm{M}^{n}\right)=\left[k_{\mathrm{d}}+\right.$ $\left.k_{\mathrm{i} 2}(\mathrm{LOOH})+k_{\mathrm{a} 1}(\mathrm{AH})\right]\left(\mathrm{M}^{n+1}\right)$

We thus deduce: $R_{\mathrm{i} 2}=\frac{R_{\mathrm{i} 1}}{1+\frac{C_{\mathrm{d}}+\mathrm{AE}_{1}(\mathrm{AH})}{(\mathrm{LOOH})}}$ with $C_{\mathrm{d}}=k_{\mathrm{d}} / k_{\mathrm{i} 2}$

Finally, one has: $-\mathrm{d}\left(\mathrm{M}^{n}\right) / \mathrm{d} t=R_{\mathrm{i} 1}-R_{\mathrm{i} 2}-R_{\mathrm{a} 1}$

In the absence of an antioxidant, we simply have:

$$
\begin{gathered}
R_{\mathrm{p}}^{0}=k_{2}(\mathrm{LOO})(\mathrm{LH})-k_{\mathrm{i} 1}(\mathrm{LOOH})\left(\mathrm{M}^{n}\right)-k_{\mathrm{i} 2}(\mathrm{LOOH})\left(\mathrm{M}^{n+1}\right) \\
=R_{2}-R_{\mathrm{i} 1}-R_{\mathrm{i} 2} \\
{ }^{c} \\
R_{\mathrm{i} 2}=2 k_{\mathrm{t}}\left(\mathrm{LOO}^{2}\right)^{2}
\end{gathered}
$$

We thus deduce:

$$
R_{\mathrm{p}}^{0}=r_{2}(\mathrm{LH}) R_{\mathrm{i} 2}{ }^{1 / 2}-R_{\mathrm{i} 1}-R_{\mathrm{i} 2}
$$

with $r_{2}=k_{2} /\left(2 k_{\mathrm{t}}\right)^{1 / 2}$

$$
R_{\mathrm{i} 2}=\frac{R_{\mathrm{i} 1}}{1+\frac{C_{\mathrm{d}}}{(\mathrm{LOOH})}}
$$

Parameters $k_{\mathrm{a}}, r_{2}$ and $\mathrm{AE}_{2}$ are also bound through the following relationship:

$$
k_{\mathrm{a}}=\left(r_{2} \mathrm{AE}_{2}\right)^{2} / 2
$$

In a first step, the curves of uninhibited lipid peroxidation are analyzed to estimate parameters $r_{2}$ (a measure of the oxidizability of linoleic acid in the medium) and $k_{\mathrm{i} 1}$ (rate constant of LOOH cleavage by low-valence heme). Then, using this set of parameters, the curves of inhibited lipid peroxidation are analyzed to estimate the antioxidant efficiencies $\left(\mathrm{AE}_{1}, \mathrm{AE}_{2}\right)$ and stoichiometry $(n)$. The parameter $n$ is defined as the number of oxidizing equivalents (hypervalent iron and/or lipid peroxyl radicals) trapped per antioxidant molecule. It is implemented in the program by the following initial condition: AH concentration $=n \times$ total antioxidant concentration. Heme degradation (measured by parameter $C_{\mathrm{d}}$ ) is negligible during the short time period selected to monitor uninhibited peroxidation. In the presence of an antioxidant, the peroxidation is monitored over much longer time periods and $C_{\mathrm{d}}$ must be taken into account as an additional adjustable parameter.

\section{Annex 2: mathematical treatment for the inhibition of lipid peroxidation induced by non-heme iron}

The new scheme is as follows:

Initiation

$$
\begin{gathered}
\mathrm{M}^{n}+\mathrm{LOOH} \rightarrow \mathrm{M}^{n+1}+\mathrm{LO}, k_{\mathrm{i}} \\
\mathrm{LO}+\mathrm{LH}+\mathrm{O}_{2} \rightarrow \mathrm{LOH}+\mathrm{LOO}, k_{1}
\end{gathered}
$$

Propagation

$$
\mathrm{LOO}+\mathrm{LH}+\mathrm{O}_{2} \rightarrow \mathrm{LOOH}+\mathrm{LOO}, k_{2}
$$

Termination

$$
2 \mathrm{LOO}^{*} \rightarrow \text { non-radical products, } k_{\mathrm{t}}
$$

Inhibition of initiation

$$
\mathrm{LO}+\mathrm{AH} \rightarrow \mathrm{LOH}+\mathrm{A}, k_{\mathrm{a} 1}
$$

Inhibition of propagation

$$
\mathrm{LOO}+\mathrm{AH} \rightarrow \mathrm{LOOH}+\mathrm{A}, k_{\mathrm{a} 2}
$$


Assuming a steady-state for LO, one gets:

$R_{\mathrm{i}}=k_{\mathrm{i}}(\mathrm{LOOH})\left(\mathrm{M}^{n}\right)=k_{1}(\mathrm{LH})(\mathrm{LO})+k_{\mathrm{a} 1}(\mathrm{AH})(\mathrm{LO})=R_{1}+R_{\mathrm{a} 1}$

We thus deduce:

$$
R_{1}=\frac{k_{\mathrm{i}}(\mathrm{LOOH})\left(\mathrm{M}^{n}\right)}{1+\mathrm{AE}_{1}(\mathrm{AH}) /(\mathrm{LH})}
$$

with $\mathrm{AE}_{1}=k_{\mathrm{a} 1} / k_{1}$ (antioxidant efficiency at inhibiting initiation).

The peroxidation rate is:

$$
\begin{gathered}
R_{\mathrm{p}}=\mathrm{d}(\mathrm{LOOH}) / \mathrm{d} t=k_{2}\left(\mathrm{LOO}^{\prime}\right)(\mathrm{LH})+k_{\mathrm{a} 2}\left(\mathrm{LOO}^{\prime}\right)(\mathrm{AH}) \\
-k_{\mathrm{i}}(\mathrm{LOOH})\left(\mathrm{M}^{n}\right)=R_{2}+R_{\mathrm{a} 2}-R_{\mathrm{i}}
\end{gathered}
$$

The rate of lipid consumption is: $-\mathrm{d}(\mathrm{LH}) / \mathrm{d} t=R_{1}+R_{2}$ The rate of antioxidant consumption is:

$$
\begin{aligned}
R_{\mathrm{a}} & =-\mathrm{d}(\mathrm{AH}) / \mathrm{d} t=k_{\mathrm{a} 1}\left(\mathrm{LO}^{\prime}\right)(\mathrm{AH})+k_{\mathrm{a} 2}\left(\mathrm{LOO}^{\prime}\right)(\mathrm{AH}) \\
& =R_{1} \mathrm{AE}_{1}(\mathrm{AH}) /(\mathrm{LH})+R_{\mathrm{a} 2}
\end{aligned}
$$

Assuming a steady-state for the lipid peroxyl radicals, one gets:

$$
R_{1}=k_{\mathrm{a} 2}\left(\mathrm{LOO}^{\prime}\right)(\mathrm{AH})+2 k_{\mathrm{t}}\left(\mathrm{LOO}^{\prime}\right)^{2}
$$

Solving for (LOO) gives:

$$
\left(\mathrm{LOO}^{*}\right)=\frac{k_{\mathrm{a} 2}(\mathrm{AH})}{4 k_{\mathrm{t}}}\left[\left(1+\frac{8 k_{\mathrm{t}} R_{1}}{k_{\mathrm{a} 2}{ }^{2}(\mathrm{AH})^{2}}\right)^{1 / 2}-1\right]
$$

Hence, we deduce:

$$
R_{\mathrm{a} 2}=k_{\mathrm{a}}(\mathrm{AH})^{2}\left[\left(1+\frac{2 R_{1}}{k_{\mathrm{a}}(\mathrm{AH})^{2}}\right)^{1 / 2}-1\right]
$$

with $k_{\mathrm{a}}=k_{\mathrm{a} 2}^{2} /\left(4 k_{\mathrm{t}}\right)$

We also have:

$R_{2}=\frac{R_{\mathrm{a} 2}(\mathrm{LH})}{\mathrm{AE}_{2}(\mathrm{AH})}$ with $\mathrm{AE}_{2}=k_{\mathrm{a} 2} / k_{2}$ (antioxidant efficiency at inhibiting propagation).

$$
\text { Finally, }-\mathrm{d}\left(\mathrm{M}^{n}\right) / \mathrm{d} t=\mathrm{d}\left(\mathrm{M}^{n+1}\right) / \mathrm{d} t=R_{\mathrm{i}}
$$

In the absence of antioxidant, we simply have:

$$
\begin{gathered}
\left.R_{1}=R_{\mathrm{i}}=2 k_{\mathrm{t}}\left(\mathrm{LOO}^{\prime}\right)^{2} \text { (steady state for } \mathrm{LO}^{\prime} \text { and } \mathrm{LOO}^{\prime}\right) \\
R_{\mathrm{p}}^{0}=R_{2}-R_{\mathrm{i}}=r_{2}(\mathrm{LH}) R_{\mathrm{i}}{ }^{1 / 2}-R_{\mathrm{i}}
\end{gathered}
$$

\section{Acknowledgements}

The present work has received funding from the European Community's Seventh Framework Programme. This funding was attributed to the Colorspore project entitled New sources of natural, gastric stable, food additives, colorants and novel functional foods (small collaborative project no. 207948, topic Biotechnologies for the production of food additives, colorants and flavours, KBBE-2007-2-3-03).

\section{References}

1 E. Choe and D. B. Min, Chemistry and reactions of reactive oxygen species in foods, Crit. Rev. Food Sci. Nutr., 2006, 46, $1-22$.

2 E. Niki, Y. Yoshida, Y. Saito and N. Noguchi, Lipid peroxidation: mechanisms, inhibition and biological effects, Biochem. Biophys. Res. Commun., 2005, 338, 668-676.

3 H. Yin, L. Xu and N. A. Porter, Free radical lipid peroxidation: mechanisms and analysis, Chem. Rev., 2011, 111, 5944-5972.

4 G. Spiteller, Peroxyl radicals: inductors of neurodegenerative and other inflammatory diseases. Their origin and how they transform cholesterol, phospholipids, plasmalogens, polyunsaturated fatty acids, sugars, and proteins into deleterious products, Free Radical Biol. Med., 2006, 41, 362387.

5 J. W. Stephens, M. P. Khanolkar and S. C. Bain, The biological relevance and measurement of plasma markers of oxidative stress in diabetes and cardiovascular disease, Atherosclerosis, 2009, 202, 321-329.

6 L. M. Sayre, G. Perry and M. A. Smith, Oxidative stress and neurotoxicity, Chem. Res. Toxicol., 2008, 21, 172-188.

7 M. Valko, C. J. Rhodes, J. Moncol, M. Izakovic and M. Mazur, Free radicals, metals and antioxidants in oxidative stressinduced cancer, Chem.-Biol. Interact., 2006, 160, 1-40.

8 G. Lombardi-Boccia, B. Martinez-Dominguez and A. Aguzzi, Total heme and non-heme iron in raw and cooked meats, J. Food Sci., 2002, 67, 1738-1741.

9 C. P. Baron and H. J. Andersen, Myoglobin-induced lipid oxidation. A review, J. Agric. Food Chem., 2002, 50, 3887-3897.

10 C. Faustman, Q. Sun, R. Mancini and S. P. Suman, Myoglobin and lipid oxidation interactions: mechanistic bases and control, Meat Sci., 2010, 86, 86-94.

$11 \mathrm{~J}$. Kanner and T. Lapidot, The stomach as a bioreactor: dietary lipid peroxidation in the gastric fluid and the effects of plant-derived antioxidants, Free Radical Biol. Med., 2001, 31, 1388-1395.

12 T. Lapidot, R. Granit and J. Kanner, Lipid peroxidation by "free" iron ions and myoglobin as affected by dietary antioxidants in simulated gastric fluids, J. Agric. Food Chem., 2005, 53, 3293-3390.

13 B. Halliwell, K. C. Zhao and M. Whiteman, The gastrointestinal tract: a major site of antioxidant action?, Free Radical Res., 2000, 33, 819-830.

14 B. Halliwell, J. Rafter and A. Jenner, Health promotion by flavonoids, tocopherols, tocotrienols, and other phenols: direct or indirect effects? Antioxidant or not?, Am. J. Clin. Nutr., 2005, 81, 268S-276S.

15 E. Vulcain, P. Goupy, C. Caris-Veyrat and O. Dangles, Inhibition of the metmyoglobin-induced peroxidation of 
linoleic acid by dietary antioxidants: action in the aqueous vs. lipid phase, Free Radical Res., 2005, 39, 547-563.

16 P. Goupy, E. Vulcain, C. Caris-Veyrat and O. Dangles, Dietary antioxidants as inhibitors of the heme-induced peroxidation of linoleic acid: mechanism of action and synergism, Free Radical Biol. Med., 2007, 43, 933-946.

17 P. Goupy, E. Reynaud, O. Dangles and C. Caris-Veyrat, Antioxidant activity of (all-E)-lycopene and synthetic apolycopenoids in a chemical model of oxidative stress in the gastro intestinal tract, New J. Chem., 2012, 36, 575-587.

18 B. Lorrain, O. Dangles, C. Genot and C. Dufour, Chemical modeling of heme-induced lipid oxidation in gastric conditions and inhibition by dietary polyphenols, J. Agric. Food Chem., 2010, 58, 676-683.

19 B. Lorrain, O. Dangles, M. Loonis, M. Armand and C. Dufour, Dietary iron-initiated lipid oxidation and its inhibition by polyphenols in gastric conditions, J. Agric. Food Chem., 2012, 60, 9074-9081.

20 R. Khaneja, L. Perez-Fons, S. Fakhry, L. Baccigalupi, S. Steiger, E. To, G. Sandmann, T. C. Dong, E. Ricca, P. D. Fraser and S. M. Cutting, Carotenoids found in Bacillus, J. Appl. Microbiol., 2010, 108, 1889-1902.

21 H. A. Hong, J. M. Huang, R. Khaneja, L. V. Hiep, M. C. Urdaci and S. M. Cutting, The safety of Bacillus subtilis and Bacillus indicus as food probiotics, J. Appl. Microbiol., 2008, 105, 510520.

22 L. Perez-Fons, S. Steiger, R. Khaneja, P. M. Bramley, S. M. Cutting, G. Sandmann and P. D. Fraser, Identification and the developmental formation of carotenoid pigments in the yellow/orange Bacillus sporeformers, Biochim. Biophys. Acta, 2011, 1811, 177-185.

23 A. Mortensen, Supplements, in Carotenoids, Vol. 5: Nutrition and Health, ed. G. Britton, S. Liaaen-Jensen and H. Pfander, Birkhaueser Verlag AG, Basel, Switzerland, 2009, pp. 67-82.

24 V. Tyssandier, E. Reboul, J.-F. Dumas, C. BougteloupDemange, M. Armand, J. Marcand, M. Sallas and P. Borel, Processing of vegetable-borne carotenoids in the human stomach and duodenum, Am. J. Physiol., 2003, 284, G913G923.

25 A. Mikkelsen and L. H. Skibsted, Acid-catalysed reduction of ferrylmyoglobin: product distribution and kinetics of autoreduction and reduction by NADH, Z. Lebensm.-Unters. Forsch., 1995, 200, 171-177.

26 G. Britton, UV/visible spectroscopy, in Carotenoids, Vol. 1B: Spectroscopy, ed. G. Britton, S. Liaaen-Jensen and $\mathrm{H}$. Pfander, Birkhaueser Verlag AG, Basel, Switzerland, 1995, pp. 13-62.

27 J. R. Marshall and G. J. Wilmoth, Pigments of Staphylococcus aureus, a series of triterpenoid carotenoids, J. Bacteriol., 1981, 147, 900-913.

28 J. R. Mancuso, D. J. McClements and E. A. Decker, Ability of iron to promote surfactant peroxide decomposition and oxidize alpha-tocopherol, J. Agric. Food Chem., 1999, 47, 4146-4149.

29 H. El Hajji, E. Nkhili, V. Tomao and O. Dangles, Interactions of quercetin with iron and copper ions: complexation and autoxidation, Free Radical Res., 2006, 40, 303-320.
30 E. Södergren, J. Nourooz-Zadeh, L. Berglund and B. Vessby, Re-evaluation of the ferrous oxidation in xylenol orange assay for the measurement of plasma lipid hydroperoxides, J. Biochem. Biophys. Methods, 1998, 37, 137-146.

31 K. D. Welch, T. Z. Davis and S. D. Aust, Iron autoxidation and free radical generation: effects of buffer, ligands and chelators, Arch. Biochem. Biophys., 2002, 397, 360369.

32 E. Goicoechea, E. F. A. Brandon, M. H. Blokland and M. D. Guillen, Fate in digestion in vitro of several food components, including some toxic compounds coming from omega-3 and omega-6 lipids, Food Chem. Toxicol., 2011, 49, 115-124.

33 R. Olivero David, S. Bastida, A. Schultz, L. Gonzales Torres, M. J. Gonzales-Munoz, F. J. Sanchez-Muniz and J. Benedi, Fasting status and thermally oxidized sunflower oil ingestion affect the intestinal antioxidant enzyme activity and gene expression of male Wistar rats, J. Agric. Food Chem., 2010, 58, 2498-2504.

34 I. Staprans, X.-M. Pan, J. H. Rapp and K. R. Feingold, The role of dietary oxidized cholesterol and oxidized fatty acids in the development of atherosclerosis, Mol. Nutr. Food Res., 2005, 49, 1075-1082.

35 F. Pierre, S. Tache, F. Gueraud, A. L. Rerole, M.-L. Jourdan and C. Petit, Apc mutation induces resistance of colonic cells to lipoperoxide-triggered apoptosis induced by faecal water from haem-fed rats, Carcinogenesis, 2007, 28, 321327.

36 J. Kanner, S. Gorelik, S. Roman and R. Kohen, Protection by polyphenols of postprandial human plasma and low-density lipoprotein modification: the stomach as a bioreactor, J. Agric. Food Chem., 2012, 60, 8790-8796.

37 M. Golding and T. J. Wooster, The influence of emulsion structure and stability on lipid digestion, Curr. Opin. Colloid Interface Sci., 2010, 15, 90-101.

38 L. H. Skibsted, Carotenoids in antioxidant networks. Colorants or radical scavengers, J. Agric. Food Chem., 2012, 60, 2409-2417.

39 A. El-Agamey, G. M. Lowe, D. J. McGarvey, A. Mortensen, D. M. Phillip, T. G. Truscott and A. J. Young, Carotenoid radical chemistry and antioxidant/pro-oxidant properties, Arch. Biochem. Biophys., 2004, 430, 37-48.

40 Y. L. Gao and L. D. Kispert, Reaction of carotenoids and ferric chloride: equilibria, isomerization and products, J. Phys. Chem. B, 2003, 107, 5333-5338.

41 A. Martinez, M. A. Rodriguez-Girones, A. Barbosa and M. Costas, Donator acceptor map for carotenoids, melatonin and vitamins, J. Phys. Chem. A, 2008, 112, 90379042.

42 M. Burke, R. Edge, E. J. Land, D. J. McGarvey and T. G. Truscott, One-electron reduction potentials of dietary carotenoid radical cations in aqueous micellar environments, FEBS Lett., 2001, 500, 132-136.

43 L. Mei, D. J. McClements and E. A. Decker, Lipid oxidation in emulsions as affected by charge status of antioxidants and emulsion droplets, J. Agric. Food Chem., 1999, 47, 2267-2273. 
44 C. Berton, M.-H. Ropers, D. Bertrand, M. Viau and C. Genot, Oxidative stability of oil-in-water emulsions stabilised with protein or surfactant emulsifiers in various oxidation conditions, Food Chem., 2012, 131, 1360-1369.

45 S. Kiokias, C. Dimakou and V. Oreopoulou, Activity of natural carotenoid preparations against the autoxidative deterioration of sunflower oil-in-water emulsions, Food Chem., 2009, 114, 1278-1284.
$46 \mathrm{Z}$. Cheng and Y. Li, What is responsible for the initiating chemistry of iron-mediated lipid peroxidation: an update, Chem. Rev., 2007, 107, 748-766.

47 H. Sies, W. Stahl and A. Sevanian, Nutritional, dietary and postprandial oxidative stress, J. Nutr., 2005, 135, 969-972.

48 C. P. Baron and L. H. Skibsted, Prooxidative activity of myoglobin species in linoleic acid emulsions, J. Agric. Food Chem., 1997, 45, 1704-1710. 